\title{
Evaluation of High-Resolution Gridded Precipitation Data in Arid and Semiarid Regions: Heihe River Basin, Northwest China
}

\author{
YI YANG AND JIANPING TANG \\ School of Atmospheric Sciences, Institute for Climate and Global Change Research, Nanjing University, and CMA-NJU \\ Joint Laboratory for Climate Prediction Studies, Nanjing University, Nanjing, China
}

\section{ZHE XIONG}

Key Laboratory of Regional Climate-Environment for Temperate East Asia, Institute of Atmospheric Physics, Chinese Academy of Sciences, Beijing, China

\author{
XINNING DONG \\ Chongqing Climate Center, Chongqing, China
}

(Manuscript received 26 October 2016, in final form 4 September 2017)

\begin{abstract}
The reliability of three satellite-derived precipitation products, Tropical Rainfall Measuring Mission (TRMM) 3B42 V7 and the Climate Prediction Center morphing technique (CMORPH) satellite-only (CMORPH-RAW) and gauge-corrected versions (CMORPH-CRT), and three gauge-based precipitation datasets, Asian Precipitation-Highly Resolved Observational Data Integration Toward Evaluation of Water Resources (APHRODITE), National Climate Center of China Meteorological Administration (CN05.1), and Institute of Tibetan Plateau Research, Chinese Academy of Sciences (ITPCAS), is evaluated via comparisons with rain gauge observations from stations over the Heihe River basin (HRB) for the period from 1998 to 2012. The results show that the observed climatology, interannual variability, the detection of precipitation events, and probability density functions (PDFs) are reasonably well represented by the highresolution precipitation products (HRPPs), with APHRODITE presenting the best performance, CN05.1 and ITPCAS exhibiting similar performances, and CMORPH-CRT showing a poor performance. The biascorrection algorithms applied in CMORPH-CRT improve the accuracy of CMORPH-RAW slightly but fail to improve the rainfall detection skill. TRMM consistently outperforms CMORPH-CRT at various scales, whereas CMORPH-CRT is comparable to TRMM in summer. The spatial correlations, normalized rootmean-square error (NRMSE), and probability of detection (POD) show that all datasets perform better in summer than in winter. Except for CMORPH-RAW, the HRPPs could adequately reproduce the unimodal characteristics of annual cycle, although they overestimate the magnitude of the warm season precipitation. The HRPPs could capture the overall spatial distribution and decadal trend of extreme precipitation indices. However, the satellite-derived products overestimate the wet day precipitation and underestimate the consecutive dry days, although the TRMM generates relatively better results.
\end{abstract}

\section{Introduction}

Precipitation is a vital part of the hydrological cycle and a key parameter for various applications related to water resources. Accurate and reliable information on the spatiotemporal distribution of precipitation is critical for hydrological research and water resources management in areas that utilize water, such as agricultural, industrial, and urban areas. Precipitation is the main

Corresponding author: Jianping Tang, jptang@nju.edu.cn source of freshwater in many catchment areas, especially in arid and semiarid regions, such as the HRB (see appendix for acronyms and their expansions; Shen and Chen 2010; Cheng et al. 2014). Traditionally, rain gauge observations have been shown to provide relatively accurate point measurements of precipitation amounts as compared with other data sources like weather radars (Xie and Arkin 1995). However, the inhomogeneous distribution and poor spatial and temporal resolution of rain gauge networks do not adequately represent the spatial variability of rainfall, especially over regions with 
complex terrain and arid and semiarid areas (New et al. 2001; Villarini et al. 2008). To make up for the sparsity of stations and to better understand the precipitation variability, data with high spatial-temporal resolution must be obtained from high-quality, long-term, and continuous observations.

High-resolution precipitation data are of great importance for weather monitoring, climate analysis, and hydrological studies because they can effectively overcome the limits of sparse and uneven rain gauge distribution. Over the past 10 years, several HRPPs $\left(0.25^{\circ}\right)$ have been developed (Maggioni et al. 2016). Certain HRPPs are based on remote sensing techniques, such as the TRMM Multisatellite Precipitation Analysis (TMPA or TRMM 3B42 V7; Huffman and Bolvin 2013) and CMORPH (Joyce et al. 2004). Other HRPPs are based on readily available rain gauge observations and the usage of different interpolation techniques, such as APHRODITE (hereafter referred to as APHRO; Yatagai et al. 2012). Quantitative evaluation of HRPPs is needed to provide feedback to the product developers and to determine the proper products for the application (Kidd et al. 2012). In response to this need, many studies have been conducted to evaluate satellite precipitation products at a regional scale (Turk et al. 2008; Zhou et al. 2008; Habib et al. 2009; J. F. Liu et al. 2010; Shen et al. 2010; Tian et al. 2010; Salio et al. 2015; Prakash et al. 2015; Jiang et al. 2016). Although satellite-derived HRPPs provide a superior range of continuous observation, they share the challenges of retrieving precipitation during winter because of the prevalence of low-intensity precipitation events and cold surface backgrounds affecting the PMW retrievals, and the estimation accuracy is better in summer (Maggioni et al. 2016). These products can provide accurate descriptions of precipitation over wet regions, although the accuracy is limited over arid and semiarid areas (Ebert et al. 2007; Xie et al. 2007; Thiemig et al. 2012; Maggioni et al. 2016). Great efforts have also been made to validate daily gauge-based high-resolution precipitation data (Ghajarnia et al. 2015; Tan et al. 2015). Compared with TRMM 3B42 and TRMM 2B31, APHRO can better describe the monthly and annual variability of precipitation along the Himalayas (Andermann et al. 2011), but it tends to underestimate the trends of summer precipitation in eastern China (Han and Zhou 2012). Although there have been many intercomparison studies aimed at evaluating HRPPs, evaluation studies and comparison of HRPPs over northwestern China are rare (Wu et al. 2013; He et al. 2015; Yang and Luo 2014).

Located in an arid and semiarid region of northwestern China, the HRB is the second largest inland river basin and displays a typical continental climate. Precipitation is one of the most important water resources over the HRB. Many studies have been conducted to investigate the spatiotemporal characteristics and the impact factors of precipitation over the HRB (Ding et al. 1999; Xiong and Yan 2013; Pan et al. 2014; Zeng and Yang 2016). Cao and Dou (2005) reported that there is an increase in annual precipitation over all subregions divided by the rotated empirical orthogonal function method. Multiple linear regression analyses have indicated that with increases of altitude, the annual precipitation increases from west to east and from north to south (Ding et al. 1999) and is mainly concentrated in upstream regions (Ding et al. 2009). The seasonal distribution of precipitation is uneven, with higher values during June and September that account for $73.3 \%$ of the annual totals. In addition to the surface precipitation climatology over the HRB, Cheng et al. (2015) addressed the changes in rainfall extremes based on extreme indices and station observations and found that the CDD show a decreasing trend at most stations, whereas an opposite trend is detected for the indices related to rainfall amount over the basin except in the downstream region. These studies that used rain gauge observations have shown considerable spatiotemporal variability of precipitation. However, because of the complex terrain and semiarid environment over the HRB, the spatial distribution of stations is sparse and uneven, which limits the representation of precipitation variability, especially at small spatial scales. HRPPs can provide spatially continuous precipitation data that can effectively overcome the disadvantages caused by the uneven and sparse distributions of rain gauge observations. Although evaluations of HRPPs are of primary importance for regional hydrological process studies and water resources management over the HRB, few studies have been conducted to date.

Because of the inevitable errors generated by different sources of datasets, an HRPP must be calibrated and evaluated prior to application. The aim of this study is to evaluate the performance of six high-resolution precipitation datasets, which include the TRMM 3B42, CMORPH-RAW, CMORPH-CRT, and APHRO products, and two rain-gauge-based, high-resolution precipitation products from the National Climate Center of China Meteorological Administration (hereafter CN05.1; Wu and Gao 2013) and the hydrometeorological research group at the Institute of Tibetan Plateau Research, Chinese Academy of Sciences (hereafter ITPCAS; He 2010), via comparisons with high-quality controlled surface observations (observations will denote gauge data) over the HRB. The spatiotemporal characteristics of the mean climatology 
and extreme indices are analyzed. The results of the study can provide data users with an understanding of the accuracy and limitations of precipitation data and will contribute to the management of agricultural irrigation over the river basin. The remainder of this paper is arranged as follows. Section 2 presents a description of the study area, section 3 describes the data and methods, section 4 provides a detailed analysis of the highresolution precipitation data over the HRB, and section 5 presents the summary and concluding remarks.

\section{Study area}

The HRB extends between the latitudes $37^{\circ} 42^{\prime}$ and $43^{\circ} 18^{\prime} \mathrm{N}$ and between the longitudes $96^{\circ} 6^{\prime}$ and $104^{\circ} 12^{\prime} \mathrm{E}$ (Fig. 1), and it drains an area of $290000 \mathrm{~km}^{2}$. Affected by the westerly circulation and the polar cold air mass, the climate of the basin is continental, with extremely dry conditions in winter and wet conditions in summer. The Heihe River rises from the middle part of the Qilian Mountains and flows past Qinghai, Gansu, and Inner Mongolia from south to north. The basin has complex topography and ecosystems that range from mountains to plains, oases, and deserts with higher altitudes in the southern and western regions.

The HRB can be subdivided into three different climatic zones: 1) the cold and humid or semiarid upper mountain reaches, 2) the midstream temperate zone, and 3) the downstream warm temperate zone. Situated at the upstream end of the basin is a national nature reserve, where the water source is predominantly glacial meltwater in addition to natural precipitation. The middle section of the HRB is a national commodity grain base with annual precipitation ranging from 100 to $200 \mathrm{~mm}$. Along with socioeconomic development, water use in the midstream region has increased sharply (Ma et al. 2011), and human activities have changed the distribution of the lakes and watershed and the interannual allocation of water resources. The ecological environment is fragile, and agricultural production has been greatly affected by climate change. The downstream reach is in the Badain Jaran Desert, China's third largest and the world's fourth largest desert. The potential evapotranspiration in this region is more than $1000 \mathrm{~mm}$. The continued sustained socioeconomic development of the HRB is vulnerable to hydroclimatic variation because of its limited water resources and fragile ecosystems. In recent years, the HRB has suffered from serious water scarcity problems similar to other river basins in northwest China (Cheng 2002), and these problems have become the major bottleneck for socioeconomic development and ecological security (Li et al. 2013).

\section{Data and methods}

\section{a. High-resolution precipitation products}

Six high-resolution precipitation datasets based on satellite data or precipitation station observations, namely, TRMM 3B42, CMORPH-RAW, CMORPHCRT, APHRO, CN05.1, and ITPCAS, are evaluated. Most of these HRPPs are available at a spatial resolution of $0.25^{\circ} \times 0.25^{\circ}$, except for ITPCAS, which has a higher spatial resolution of $0.1^{\circ}$. Table 1 lists the basic information on the spatial resolution, coverage, and available periods for all six products.

TRMM 3B42 (V7) (post-real time) presents precipitation products from the TMPA (Huffman and Bolvin 2013). The PMW and IR estimates are combined by using the PMW data where available and PMW-calibrated IR estimates elsewhere. The gauge-adjustment procedure is based on the Global Precipitation Climatology Centre (GPCC) monthly gauge data including national standard stations over HRB (Schneider et al. 2014). The latest version of the TMPA product (version 7) has not been fully evaluated with rain gauge data over the HRB. Wu et al. (2013) reported that TRMM 3B42 (V7) can well estimate the interannual variation of annual and monthly precipitation, but it overestimates the occurrence of precipitation in the upper reaches of the HRB (Peng et al. 2014; He et al. 2015).

The CMORPH dataset (Joyce et al. 2004) is a satellite precipitation product provided by the National Oceanic and Atmospheric Administration (NOAA), and it is primarily based on low-orbit satellite passive microwave observations. The geostationary IR data are used only to derive the movement of precipitation systems. The shape and intensity of the precipitation features are morphed during the time between microwave sensor scans by performing a time-weighted linear interpolation. Since 1998, CMORPH V1.0 has provided two near-real-time and bias-corrected products named CMORPH-RAW and CMORPH-CRT, respectively. CMORPH-CRT (Xie et al. 2011, 2017) is adjusted through matching the PDF of daily CMORPH-RAW against that for the CPC unified daily gauge analysis at each month over land. In this study, both CMORPH daily datasets are used so as to be consistent with the bias-corrected TRMM and to quantify the possible improvements in CMORPH-CRT.

The APHRO precipitation product (Yatagai et al. 2009), which is generated from rain gauge data obtained from National Meteorological and Hydrological Services (NHMS), precompiled datasets, and Global Telecommunication Systems (GTS) reports, is a daily highly resolved gridded precipitation dataset covering monsoon 


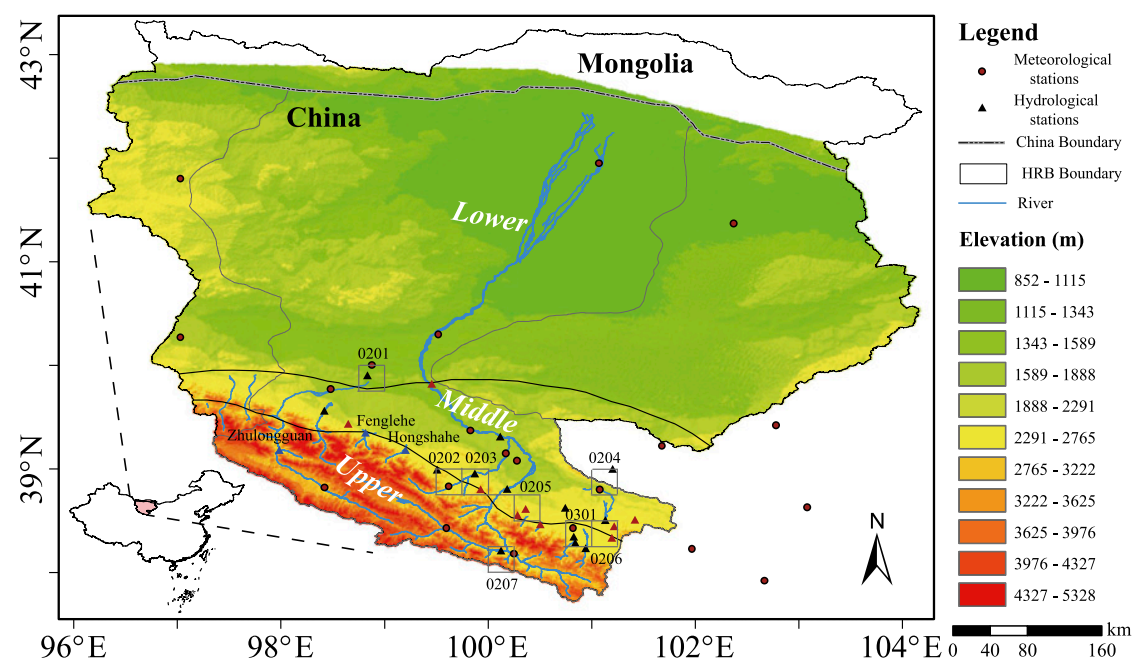

FIG. 1. Topography and station distribution map over the HRB. Two widely used boundaries of the HRB are shown in the figure, and only the larger one is used so as to cover as many rain gauges as possible. Squares represent the eight selected grid boxes $\left(0.25^{\circ} \times 0.25^{\circ}\right)$ containing at least two gauges, and the numbers indicate the grid IDs (e.g., 0204 is the fourth grid box containing two rain gauges). Nine (three) hydrological stations with locations more than $0.3^{\circ}\left(0.5^{\circ}\right)$ away from the nearest meteorological stations marked in red (blue) are used as independent validation data.

Asia, the Middle East, and Russia/northern Eurasia. Rain gauge data were interpolated using the first six harmonics of Fourier interpolation, which takes topography into account. The APHRO product includes historical data from 1951 to 2007 , and the daily gridded precipitation product APHRO_MA_V1101R2 at a $0.25^{\circ}$ resolution between 1998 and 2007 is used in this study.

The CN05.1 dataset contains daily gridded precipitation estimates based on interpolations from 2416 meteorological stations in China by the anomaly approach method, in which the gridded climatology is first calculated and then a daily anomaly is added to construct the final dataset (Wu and Gao 2013). The CN05.1 daily gridded precipitation has a $0.25^{\circ}$ resolution and has been available since 1961. The daily data between 1998 and 2012 within the area of HRB are used in this study.

The ITPCAS high-resolution dataset has a resolution of $0.1^{\circ}$ (He 2010) and is available online (http://westdc.westgis. ac.cn/data/7a35329c-c53f-4267-aa07-e0037d913a21). The dataset is constructed by merging the TRMM 3B42 and APHRO datasets and observations from 740 China Meteorological Administration (CMA) operational stations, and it is available from 1979 to 2010 . The satellite-derived TRMM served as a background field of interpolation and is applied to determine the occurrence of precipitation events, while APHRO is only used to replace TRMM that is not available beyond $40^{\circ} \mathrm{N}$. In this study, only the daily precipitation data between 1998 and 2010 are used.

To compare the evaluation results among the six HRPPs, the precipitation data from all HRPPs for the same period (1998-2012) are utilized except for APHRO (1998-2007) and ITPCAS (1998-2010) because of the temporal limitations of the datasets. All HRPPs are assessed at daily, monthly, seasonal, and annual time scales.

\section{b. Reference rain gauges}

Daily precipitation records under high quality control from 21 meteorological stations obtained from the

TABLE 1. Information on the six HRPPs used in this study.

\begin{tabular}{llccll}
\hline \hline No. & \multicolumn{1}{c}{ Name } & Spatial and temporal resolutions & Coverage & Period & Data reference \\
\hline 1 & TRMM 3B42 (V7) & $0.25^{\circ} \times 0.25^{\circ}, 3$ hourly & Global $\left(50^{\circ} \mathrm{N}-50^{\circ} \mathrm{S}\right)$ & 1998 -present & Huffman and Bolvin $(2013)$ \\
2 & CMORPH-RAW & $0.25^{\circ} \times 0.25^{\circ}, 3$ hourly & Global $\left(60^{\circ} \mathrm{N}-60^{\circ} \mathrm{S}\right)$ & 1998 -present & Joyce et al. (2004) \\
3 & CMORPH-CRT & $0.25^{\circ} \times 0.25^{\circ}, 3$ hourly & Global $\left(60^{\circ} \mathrm{N}-60^{\circ} \mathrm{S}\right)$ & 1998 -present & Xie et al. (2011) \\
4 & APHRO & $0.25^{\circ} \times 0.25^{\circ}$, daily & Eurasia $\left(55^{\circ} \mathrm{N}-15^{\circ} \mathrm{S}\right)$ & $1951-2007$ & Yatagai et al. $(2012)$ \\
5 & CN05.1 & $0.25^{\circ} \times 0.25^{\circ}$, daily & China $\left(55^{\circ} \mathrm{N}-15^{\circ} \mathrm{S}\right)$ & 1961 -present & Wu and Gao $(2013)$ \\
6 & ITPCAS & $0.10^{\circ} \times 0.10^{\circ}, 3$ hourly & China $\left(55^{\circ} \mathrm{N}-15^{\circ} \mathrm{S}\right)$ & $1979-2010$ & He $(2010)$ \\
\hline
\end{tabular}


National Meteorological Information Center of the China Meteorological Administration and from 25 hydrological stations provided by the Environment and Ecology Scientific Data Center of western China, National Natural Science Foundation of China (http:// westdc.westgis.ac.cn/) are used in this study as the ground reference data to evaluate the accuracy of the HRPPs. In total, 46 stations inside the HRB have recorded daily rainfall data for the period from 1998 to 2012 (Fig. 1). Table 2 lists the detailed information of the rain gauges. Both the meteorological and hydrological stations employ the same gauge type to measure the amount of rainfall (Yang and Ma 2014). All records from the two station groups are quality controlled before being made public and have been used in extensive studies (Y. Liu et al. 2010; Sang et al. 2013; Peng et al. 2014; Guo et al. 2016).

It is noteworthy that most of the meteorological stations have been used to generate gauge-based HRPPs (APHRO, CN05.1, and ITPCAS) on a daily basis, and some of the gauges are assimilated into satellite-based HRPPs (TRMM and CMORPH-CRT) to perform a monthly bias-correction procedure; therefore, there exists a dependency problem between the meteorological records and all HRPPs except CMORPHRAW. However, differences between HRPPs and meteorological stations may still exist due to factors such as the aggregation process and sampling frequency. All hydrological stations, installed in the source areas of rivers, have not been used to generate or calibrate HRPPs, but they are likely to be influenced by the spatial coherence of neighboring nonindependent meteorological stations, especially when the two station groups are within the same grid box (0201, 0202, 0204, 0207, and 0301 in Fig. 1). Considering the independence and sample size of the validation data, hydrological gauges located more than $0.3^{\circ}$ and $0.5^{\circ}$ away from the nearest meteorological stations, totaling 12 and 3, respectively, are selected as independent references. To make the resolution of the HRPPs comparable to that of the rain gauge data, the nearest pixel to the latitude and longitude of each station is used to provide a direct comparison with the contemporaneous ground observations (Cavazos 2000; Silva et al. 2007; McEvoy et al. 2014), and the results are similar using the bilinear interpolation among the four closest grid points (not shown; Accadia et al. 2003).

\section{c. Definition of extreme precipitation indices}

The Expert Team on Climate Change Detection and Indices (ETCCDI; http://www.clivar.org/organization/ etccdi) has developed a suite of extreme indices derived from daily precipitation and temperature data (Peterson and Manton 2008; Donat et al. 2013), and it has been widely used in the analysis of extremes in climate change studies (You et al. 2011; Sillmann et al. 2013a,b). Considering the climate characteristics of the HRB, eight precipitation extreme indices are selected in this study, and they are also used in Cheng et al. (2015). The indices can be helpful in understanding the intensity, frequency, and duration of precipitation extremes. The definitions of the indices are given in Table 3. More details are available at http://etccdi.pacificclimate.org/list_27_indices.shtml.

\section{d. Evaluation methods}

To systematically evaluate the performance of the HRPPs over the HRB, several statistical indices are introduced in this study. The RE, calculated for each HRPP-gauge data pair, is a standardized variable used to compare the accuracy of different datasets at the same level. The MRE is the mean absolute value of the RE. The Pearson correlation coefficient $r$ is used to illustrate the linear relationship between HRPPs and observations, including temporal correlation and spatial correlation, and the $t$ test is used to test for significance. The RMSE is a frequently used measure of the absolute differences between estimated and observed values (estimated values will denote HRPPs), and although it can aggregate the error magnitudes, it is scale dependent. The NRMSE facilitates the comparison between HRPPs and reference gauges with different scales. The formulas are as follows:

$$
\begin{aligned}
\mathrm{RE}_{i} & =\frac{S_{i}-O_{i}}{O_{i}} \times 100 \%, \\
\mathrm{MRE} & =\frac{1}{n} \sum_{i=1}^{n}\left|\frac{S_{i}-O_{i}}{O_{i}}\right|, \\
r & =\frac{\sum_{i=1}^{n}\left(S_{i}-\bar{S}\right)\left(O_{i}-\bar{O}\right)}{\sqrt{\sum_{i=1}^{n}\left(S_{i}-\bar{S}\right)^{2}} \sqrt{\sum_{i=1}^{n}\left(O_{i}-\bar{O}\right)^{2}}} \\
\mathrm{RMSE} & =\sqrt{\frac{1}{n} \sum_{i=1}^{n}\left(S_{i}-O_{i}\right)^{2}}, \text { and } \\
\mathrm{NRMSE} & =\frac{\sqrt{\frac{1}{n} \sum_{i=1}^{n}\left(S_{i}-O_{i}\right)^{2}}}{\frac{1}{n} \sum_{i=1}^{n} O_{i}},
\end{aligned}
$$

where $n$ is the number of pixel-point pairs, $S_{i}$ represents the HRPP estimates, $O_{i}$ represents the observed values, and $\bar{S}$ and $\bar{O}$ are the mean values of the high-resolution products and observations, respectively. 
TABLE 2. Summary of basic information for the rain gauge stations over the HRB. In the description of station type, M represents meteorological station and $\mathrm{H}$ indicates hydrological station.

\begin{tabular}{|c|c|c|c|c|c|c|}
\hline Number & Station name & Longitude $\left({ }^{\circ} \mathrm{E}\right)$ & Latitude $\left({ }^{\circ} \mathrm{N}\right)$ & Elevation (m) & Station type & Subregion \\
\hline 1 & Ejina & 101.07 & 41.95 & 940.5 & M & Lower \\
\hline 2 & Mazongshan & 97.03 & 41.80 & 1770.4 & M & Lower \\
\hline 3 & Guaizihu & 102.37 & 41.37 & 960.0 & M & Lower \\
\hline 4 & Dingxin & 99.52 & 40.30 & 1177.4 & M & Lower \\
\hline 5 & Yumenzhen & 97.03 & 40.27 & 1526.0 & M & Lower \\
\hline 6 & Jinta & 98.88 & 40.00 & 1270.5 & M & Lower \\
\hline 7 & Yuanyangchi & 98.83 & 39.91 & 1317.0 & $\mathrm{H}$ & Lower \\
\hline 8 & Zhengyixia & 99.46 & 39.82 & 1219.0 & $\mathrm{H}$ & Middle \\
\hline 9 & Jiuquan & 98.48 & 39.77 & 1477.2 & M & Middle \\
\hline 10 & Xindi & 98.42 & 39.56 & 1812.0 & $\mathrm{H}$ & Middle \\
\hline 11 & Hongshan & 98.65 & 39.44 & 1830.0 & $\mathrm{H}$ & Middle \\
\hline 12 & Yabulai & 102.78 & 39.42 & 1239.5 & M & Outsider \\
\hline 13 & Gaotao & 99.83 & 39.37 & 1332.2 & M & Middle \\
\hline 14 & Fenglehe & 98.82 & 39.35 & 1986.0 & $\mathrm{H}$ & Upper \\
\hline 15 & Pingchuan & 100.11 & 39.31 & 1335.0 & $\mathrm{H}$ & Middle \\
\hline 16 & Ayouqi & 101.68 & 39.22 & 1510.1 & M & Middle \\
\hline 17 & Hongshahe & 99.20 & 39.18 & 2249.0 & $\mathrm{H}$ & Upper \\
\hline 18 & Zhulongguan & 97.98 & 39.18 & 2842.0 & $\mathrm{H}$ & Upper \\
\hline 19 & Linze & 100.17 & 39.15 & 1453.7 & M & Middle \\
\hline 20 & Zhangye & 100.28 & 39.08 & 1482.7 & M & Middle \\
\hline 21 & Hongsihu & 101.20 & 39.00 & 1730.0 & $\mathrm{H}$ & Middle \\
\hline 22 & Dahe & 99.51 & 39.00 & 2609.0 & $\mathrm{H}$ & Upper \\
\hline 23 & Yinggezui & 99.87 & 38.96 & 1919.0 & $\mathrm{H}$ & Middle \\
\hline 24 & Sunan & 99.62 & 38.83 & 2311.8 & M & Upper \\
\hline 25 & Tuole & 98.42 & 38.82 & 3367.0 & M & Upper \\
\hline 26 & Yingluoxia & 100.18 & 38.81 & 1623.0 & $\mathrm{H}$ & Middle \\
\hline 27 & Shandan & 101.08 & 38.80 & 1764.6 & M & Middle \\
\hline 28 & Kangle & 99.92 & 38.80 & 2585.0 & $\mathrm{H}$ & Upper \\
\hline 29 & Minqin & 103.08 & 38.63 & 1367.5 & M & Outsider \\
\hline 30 & Liuba & 100.74 & 38.63 & 1826.0 & $\mathrm{H}$ & Middle \\
\hline 31 & Gaoya & 100.36 & 38.61 & 1362.0 & $\mathrm{H}$ & Middle \\
\hline 32 & Dayekou & 100.28 & 38.56 & 2591.0 & $\mathrm{H}$ & Upper \\
\hline 33 & Xiakou & 101.42 & 38.51 & 2229.0 & $\mathrm{H}$ & Middle \\
\hline 34 & Liqiao & 101.13 & 38.51 & 2134.0 & $\mathrm{H}$ & Middle \\
\hline 35 & Wafangcheng & 100.50 & 38.47 & 2345.0 & $\mathrm{H}$ & Upper \\
\hline 36 & Dahuangshan & 101.22 & 38.45 & 2434.0 & $\mathrm{H}$ & Middle \\
\hline 37 & Minle & 100.82 & 38.43 & 2281.4 & M & Upper \\
\hline 38 & Yeniugou & 99.60 & 38.43 & 3320.0 & M & Upper \\
\hline 39 & Shuangshusi & 100.83 & 38.35 & 2467.0 & $\mathrm{H}$ & Upper \\
\hline 40 & Maying & 101.19 & 38.34 & 2466.0 & $\mathrm{H}$ & Upper \\
\hline 41 & Binggoutai & 100.84 & 38.29 & 2684.0 & $\mathrm{H}$ & Upper \\
\hline 42 & Biandukou & 100.94 & 38.24 & 2752.0 & $\mathrm{H}$ & Upper \\
\hline 43 & Yongchang & 101.97 & 38.23 & 1976.9 & M & Outsider \\
\hline 44 & Zhamashike & 100.12 & 38.21 & 2645.0 & $\mathrm{H}$ & Upper \\
\hline 45 & Qilian & 100.25 & 38.18 & 2787.4 & M & Upper \\
\hline 46 & Weiwu & 102.67 & 37.92 & 1531.5 & M & Outsider \\
\hline
\end{tabular}

For quantitative evaluation of the daily HRPPs in detecting rain events, the POD, FAR, and CSI (Schaefer 1990; Wilks 2011) are calculated based on a contingency table with a threshold of $0.1 \mathrm{~mm}_{\text {day }}{ }^{-1}$. The POD indicates the fraction of rain events that are correctly detected, whereas FAR measures the fraction of rain occurrences that are falsely estimated. It is noteworthy that overestimation of rain events might generate a high
POD, but at the expense of a high FAR. The CSI, a function of POD and FAR, provides the overall fraction of events correctly detected by the HRPPs. All these indicators range from 0 to 1 , and perfect scores are $\mathrm{POD}=1, \mathrm{FAR}=0$, and CSI $=1$ :

$$
\mathrm{POD}=\frac{H}{H+M}
$$


TABLE 3. Definitions of the extreme precipitation indices.

\begin{tabular}{|c|c|c|c|}
\hline Index & Index name & Definitions & Units \\
\hline $\mathrm{CDD}$ & Consecutive dry days & $\begin{array}{l}\text { Maximum number of consecutive days with daily } \\
\text { precipitation }(\mathrm{RR})<1 \mathrm{~mm}\end{array}$ & days \\
\hline CWD & Consecutive wet days & Maximum number of consecutive days with $\mathrm{RR} \geq 1 \mathrm{~mm}$ & days \\
\hline $\mathrm{R} 10$ & Number of heavy precipitation days & Annual number of days when $\mathrm{RR} \geq 10 \mathrm{~mm}$ & days \\
\hline SDII & Simple daily intensity index & $\begin{array}{l}\text { Annual total precipitation divided by the number of } \\
\text { wet days ( } R R \geq 1 \mathrm{~mm} \text { ) in the year }\end{array}$ & $\mathrm{mm} \mathrm{day}^{-1}$ \\
\hline R95p & Very wet day precipitation & $\begin{array}{l}\text { Annual total precipitation when } \mathrm{RR}>95 \text { th percentile } \\
\text { of precipitation }\end{array}$ & $\mathrm{mm}$ \\
\hline PRCPTOT & Wet day precipitation & Annual total precipitation in wet days $(\mathrm{RR} \geq 1 \mathrm{~mm})$ & $\mathrm{mm}$ \\
\hline Rx1d & Maximum 1-day precipitation amount & Annual maximum 1-day precipitation & $\mathrm{mm}$ \\
\hline $\mathrm{Rx} 5 \mathrm{~d}$ & Maximum 5-day precipitation amount & Annual maximum consecutive 5-day precipitation & $\mathrm{mm}$ \\
\hline
\end{tabular}

$$
\begin{aligned}
\mathrm{FAR} & =\frac{F}{H+F}, \quad \text { and } \\
\mathrm{CSI} & =\frac{H}{H+M+F},
\end{aligned}
$$

where hits $H$ is the number of times that both observed and estimated rain events occurred, misses $M$ indicates the number of observed rain events not detected, and false alarms $F$ refers to the number of cases that HRPPs incorrectly estimated to be rainy but rain was not observed.

In addition, the BS and $S_{\text {score }}$ (Perkins et al. 2007) are adopted to assess the consistency between the estimated and observed PDFs. The BS reflects the mean squared error between two PDFs, whereas $S_{\text {score }}$ is the cumulative minimum value of observed and estimated frequencies for each bin and indicates the overlapping area of the PDFs. A BS of 0 and $S_{\text {score }}$ of 1 would indicate that the product perfectly generates the same probability distribution as the observation:

$$
\begin{aligned}
\mathrm{BS} & =\frac{1}{m} \sum_{i=1}^{m}\left(P_{s i}-P_{o i}\right)^{2} \quad \text { and } \\
S_{\text {score }} & =\sum_{i=1}^{m} \operatorname{Minimum}\left(P_{s i}, P_{o i}\right),
\end{aligned}
$$

where $m$ is the number of bins and $P_{s i}$ and $P_{o i}$ are the estimated and observed frequencies at each bin, respectively.

\section{Results}

\section{a. Precipitation climatology}

Figure 2 shows the spatial distribution of seasonal and annual precipitation over the HRB. The annual precipitation according to the observations is characterized by decreasing rainfall from more than $400 \mathrm{~mm}$ in the rainy southern mountain area to less than $50 \mathrm{~mm}$ in the northern plains and desert area. The spatial patterns of seasonal precipitation are consistent with that of the annual precipitation climatology and present a spatial pattern with high values in the southwest and low values in the northeast, and the precipitation is mainly concentrated in summer. For the annual precipitation from the HRPPs, the HRPPs share certain common characteristics: precipitation decreases gradually from south to north, with the most precipitation (approximately $400 \mathrm{~mm}$ ) located in the upstream region and the least precipitation (approximately $50 \mathrm{~mm}$ ) located in the downstream region. Compared with the other four HRPPs, CMORPH-RAW tends to overestimate the annual precipitation over the eastern part of the HRB and underestimate it over the southwestern basin, and the bias-corrected CMORPH-CRT improves this condition greatly. The spatial distribution of the seasonal precipitation for spring (MAM), summer (JJA), and autumn (SON) is similar to that of the annual precipitation. Pronounced spatial heterogeneity is detected for winter (DJF) precipitation, and all products, except the two CMORPH products, can represent the gradient of decreasing precipitation northeastwards, although ITPCAS tends to overestimate precipitation over the HRB. The CMORPH-RAW overestimates the winter precipitation over the eastern HRB, and the values are inconsistent with the gauge observations and the other HRPPs. Although the CMORPH-CRT shows substantial improvement in the accurate winter precipitation estimates over the eastern HRB when compared with the satellite-only CMORPH, it still shows underestimation over the southwestern basin.

To gain better insights into the biases of the HRPPs, the nearest grid point is selected to conduct direct comparisons for each rain gauge, and the MREs are calculated (Table 4). The MREs for the entire HRB are $32.19 \%$, $57.11 \%, 36.33 \%, 23.84 \%, 33.23 \%$, and $23.81 \%$ for TRMM, CMORPH-RAW, CMORPH-CRT, APHRO, CN05.1, and ITPCAS, respectively, with ITPCAS and APHRO showing the lowest errors and CMORPH-RAW showing the highest. The spatial distribution of MREs 

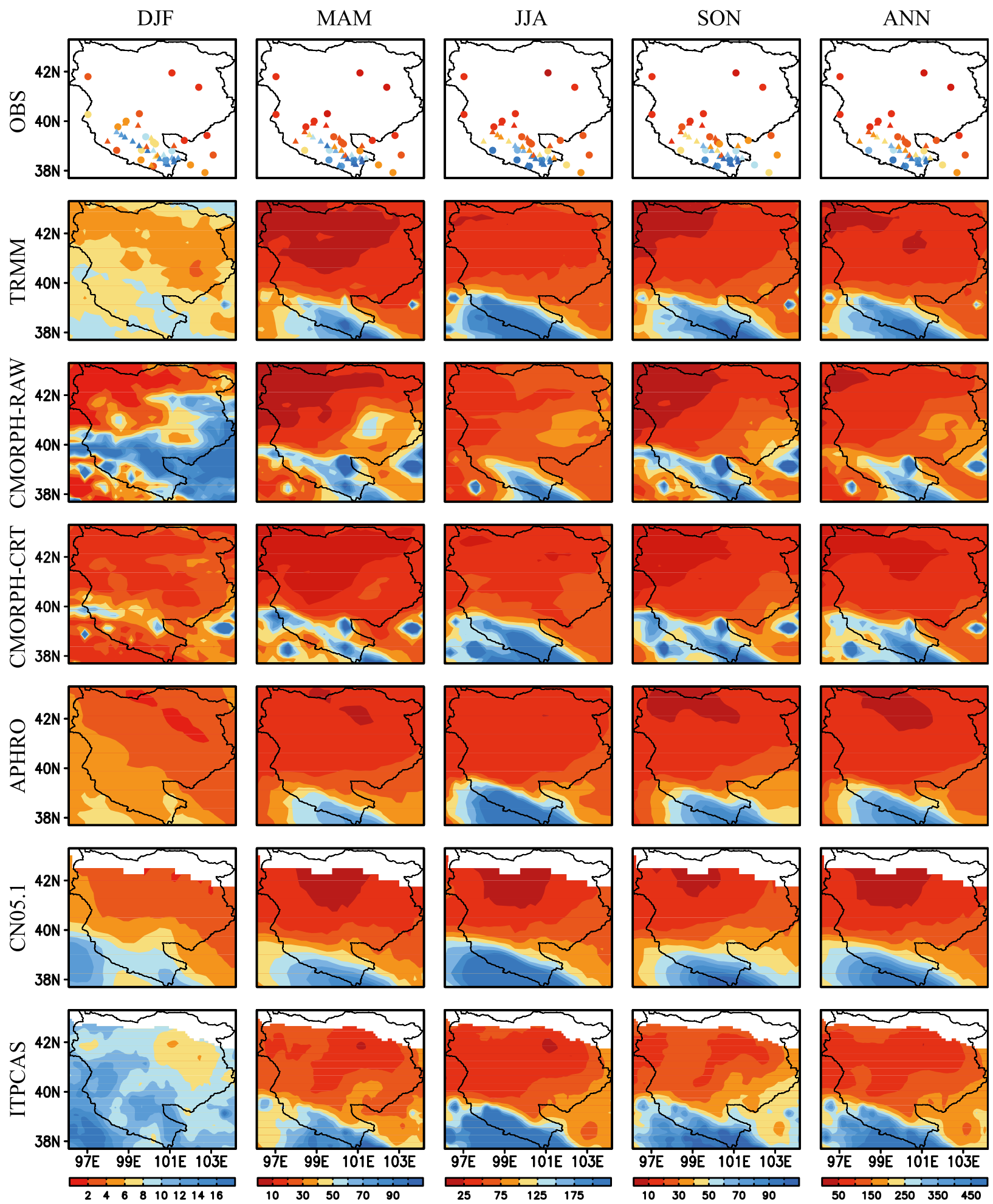

FIG. 2. Distribution of the seasonal and annual precipitation over the HRB based on observations (1998-2012), TRMM (1998-2012), CMORPH-RAW (1998-2012), CMORPH-CRT (1998-2012), APHRO (1998-2007), CN05.1 (1998-2012), and ITPCAS (1998-2010). The meteorological stations are represented by dots, and the hydrological stations are represented by triangles. 
TABLE 4. Accuracy metrics (MRE) for HRPPs with respect to the rain gauge data. Boldface indicates the best results (the minimum MRE) among the six precipitation products.

\begin{tabular}{|c|c|c|c|c|c|c|c|}
\hline \multirow[b]{2}{*}{ Time } & \multirow[b]{2}{*}{ Region } & \multicolumn{6}{|c|}{ MRE (\%) } \\
\hline & & TRMM & CMORPH-RAW & CMORPH-CRT & APHRO & CN05.1 & ITPCAS \\
\hline \multirow[t]{4}{*}{ DJF } & Upper & 56.15 & 97.71 & 77.21 & 53.57 & 66.33 & 55.95 \\
\hline & Middle & 73.04 & 233.00 & 55.78 & 50.05 & 54.58 & 108.13 \\
\hline & Lower & 159.43 & 357.18 & 80.27 & 40.83 & 40.41 & 196.92 \\
\hline & Whole & 87.83 & 234.03 & 72.83 & 50.10 & 58.33 & 112.77 \\
\hline \multirow[t]{4}{*}{ MAM } & Upper & 29.96 & 33.08 & 42.78 & 43.50 & 32.86 & 29.90 \\
\hline & Middle & 36.86 & 166.44 & 65.14 & 24.27 & 42.82 & 30.50 \\
\hline & Lower & 35.11 & 143.72 & 49.10 & 23.08 & 49.91 & 56.67 \\
\hline & Whole & 33.80 & 109.38 & 52.90 & 31.65 & 40.69 & 35.47 \\
\hline \multirow[t]{4}{*}{ JJA } & Upper & 20.35 & 21.87 & 22.51 & 16.45 & 14.54 & 11.83 \\
\hline & Middle & 56.67 & 32.93 & 60.22 & 25.59 & 50.66 & 21.83 \\
\hline & Lower & 54.83 & 87.08 & 45.38 & 18.27 & 46.08 & 7.79 \\
\hline & Whole & 40.93 & 35.27 & 40.34 & 21.30 & 34.78 & 15.73 \\
\hline \multirow[t]{4}{*}{ SON } & Upper & 24.99 & 33.83 & 34.75 & 29.54 & 22.37 & 24.15 \\
\hline & Middle & 29.65 & 104.48 & 60.20 & 26.84 & 42.23 & 32.73 \\
\hline & Lower & 31.25 & 43.31 & 25.61 & 33.24 & 41.54 & 47.10 \\
\hline & Whole & 28.02 & 63.40 & 42.31 & 28.90 & 33.89 & 31.83 \\
\hline \multirow[t]{4}{*}{ Annual } & Upper & 16.64 & 22.65 & 20.63 & 24.31 & 17.12 & 16.55 \\
\hline & Middle & 42.59 & 80.94 & 54.77 & 23.71 & 44.48 & 25.63 \\
\hline & Lower & 43.24 & 89.46 & 34.48 & 20.66 & 43.74 & 31.06 \\
\hline & Whole & 32.19 & 57.11 & 36.33 & 23.84 & 33.23 & 23.81 \\
\hline
\end{tabular}

shows obvious regional differences, with larger values over the lower reaches, which may indicate that highresolution products are more accurate for estimating the annual precipitation in the southern upper mountains than in the northern downstream deserts. However, great uncertainty remains due to the lack of gauges over the downstream area. The errors of HRPPs vary significantly in different seasons. In winter, the bias is much larger than in other seasons and the MRE is more than $100 \%$ over the whole basin for CMORPHRAW and ITPCAS. The seasonal difference in precision for satellite-based products may be related to the following: first, there occur more strong rainfall events that can be well detected by PMW sensors during the rainy season, and second, the accuracy of retrievals may be hampered by ice and snow covers in winter.

The scatterplots of the seasonal estimates from the HRPPs with respect to the surface observations within the HRB are plotted in Fig. 3. The results of two station groups are shown separately because some of the meteorological stations are assimilated into HRPPs, but it is not the case for hydrological stations. To avoid the influence of neighboring meteorological records, 12 out of 25 hydrological stations that are located more than $0.3^{\circ}$ away from the nearest meteorological stations are selected as independent ground truth, and the validation is mainly focused on the results from the independent data. The HRPPs are consistent with the observed precipitation in all seasons except winter. A possible reason for the deteriorated performance of the satellite-based HRPPs during winter is the occurrence of ice and snow cover. Striking underestimations that are consistent with the results of climatology analysis occur at hydrological stations with higher rainfall amounts in winter and spring, with CMORPH-CRT and APHRO producing the highest degree of underestimation. One source of the underestimation of APHRO is the insufficient quality control for the real-time GTS records, which sometimes report a missing value as $0 \mathrm{~mm}$ (Yatagai et al. 2012). CN05.1 and APHRO appear to be more reliable sources for seasonal precipitation than the satellite-derived datasets. TRMM is more realistic than the two CMORPH products for capturing precipitation that generally scatters around the 1:1 line, although it overestimates summer precipitation below $100 \mathrm{~mm}$. The CMORPH-RAW estimates are less consistent with the observations in all seasons, with large overestimations occurring at stations with seasonal precipitation of less than $50 \mathrm{~mm}$ and underestimations occurring at stations that present relatively greater amounts of precipitation. The CMORPHCRT reduces the overestimation significantly, but it tends to underestimate the winter precipitation above $5 \mathrm{~mm}$, which can also be found in the results of meteorological stations. As expected, the degree of dispersion decreases when the meteorological stations are considered. Overall, APHRO is closest to the hydrological rain gauges among the six HRPPs, and the results of ITPCAS and CN05.1 are also consistent with the observations. 
(a) meteorological stations
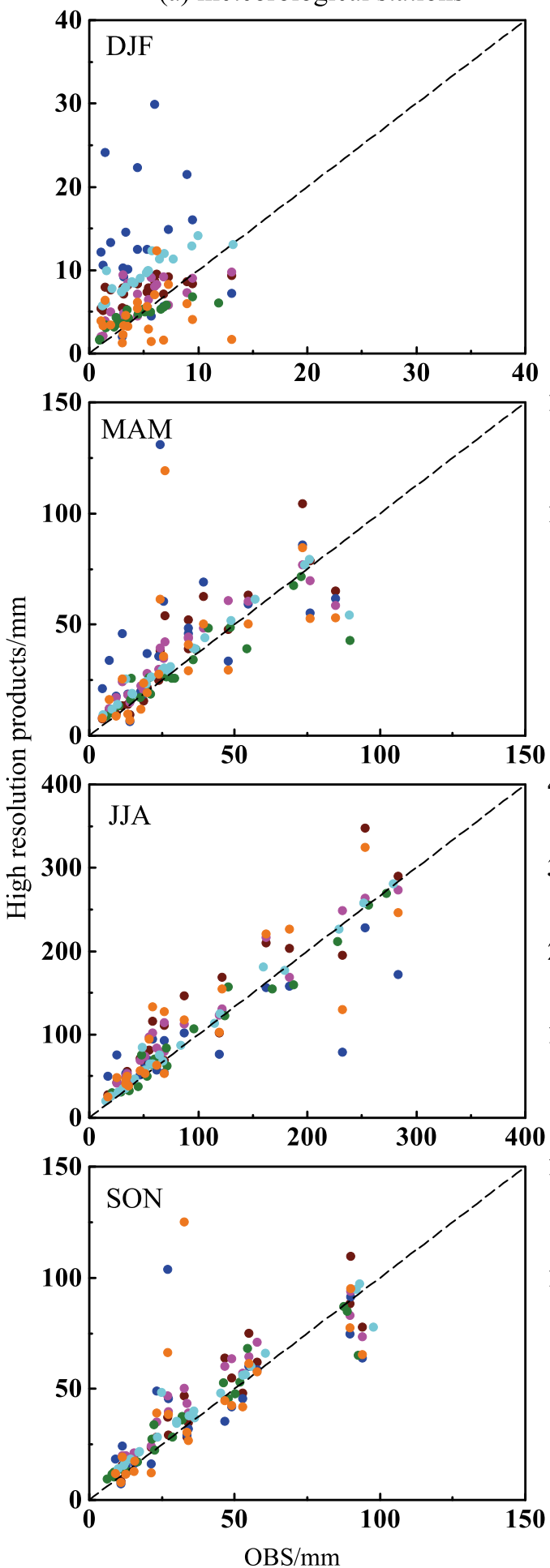

(b) hydrological stations (radius $=0.3$ )
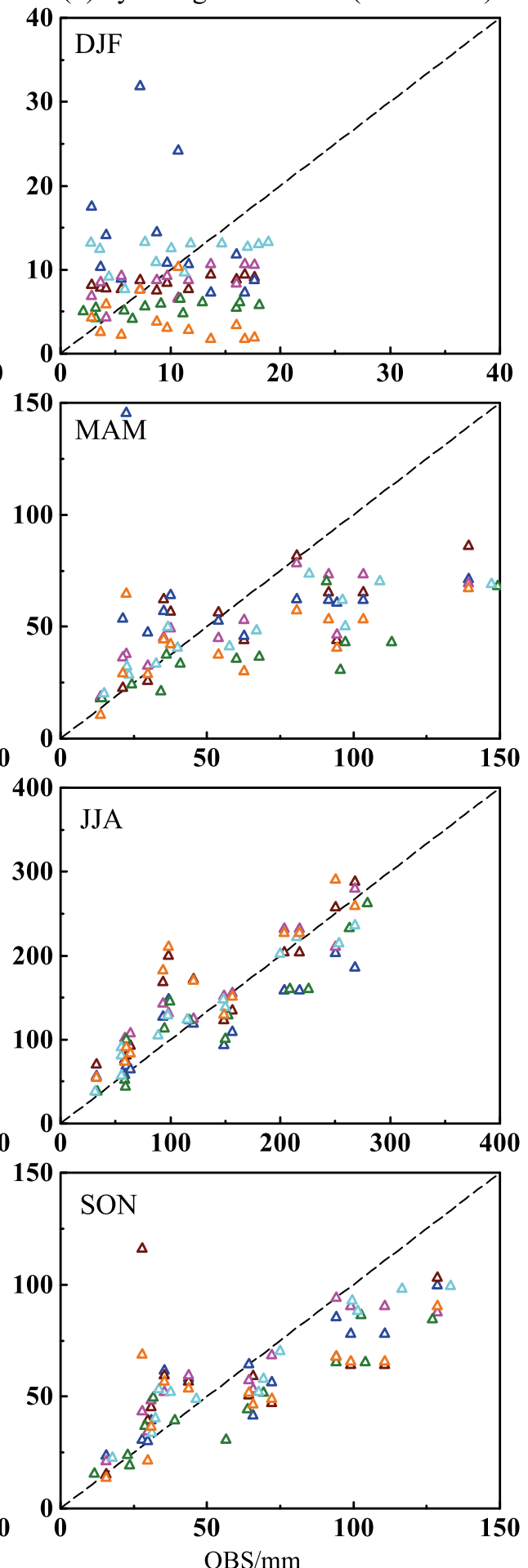

\section{- TRMM • CMORPH-RAW - CMORPH-CRT • APHRO • CN05.1 • ITPCAS}

FIG. 3. Scatterplots of seasonal mean precipitation of HRPPs for (a) meteorological stations and (b) independent hydrological stations over the HRB. The independent hydrological stations refer to the gauges located more than $0.3^{\circ}$ away from the nearest meteorological stations. The dashed line represents the 1:1 line. The meteorological stations are represented by dots, and the hydrological stations are represented by triangles. 
TABLE 5. Seasonal comparison between three hydrological stations and the nearest grid points. The categorical statistics (POD, FAR, and CSI) are calculated based on daily records in winter and summer at each pixel-point pair with a precipitation threshold of $0.1 \mathrm{~mm}$ day $^{-1}$. The bold values represent the best statistical metrics among all products.

\begin{tabular}{|c|c|c|c|c|c|c|c|}
\hline Time & Station & TRMM & CMORPH-RAW & CMORPH-CRT & APHRO & CN05.1 & ITPCAS \\
\hline \multicolumn{8}{|c|}{ NRMSE } \\
\hline \multirow[t]{3}{*}{ DJF } & Fenglehe & 0.76 & 1.25 & 1.13 & 0.82 & 0.70 & 0.66 \\
\hline & Hongshahe & 0.68 & 0.91 & 1.06 & 0.82 & 0.73 & 0.59 \\
\hline & Zhulongguan & 2.89 & 13.23 & 5.95 & 1.98 & 3.01 & 3.67 \\
\hline \multirow[t]{3}{*}{ JJA } & Fenglehe & 0.38 & 0.42 & 0.40 & 0.33 & 0.62 & 0.32 \\
\hline & Hongshahe & 0.37 & 0.47 & 0.55 & 0.36 & 0.24 & 0.36 \\
\hline & Zhulongguan & 0.53 & 0.50 & 0.41 & 0.49 & 0.47 & 0.68 \\
\hline \multicolumn{8}{|c|}{ RE (\%) } \\
\hline \multirow[t]{3}{*}{ DJF } & Fenglehe & -47.4 & -43.8 & -76.3 & -66.9 & -47.3 & -26.5 \\
\hline & Hongshahe & -50.2 & -65.1 & -89.1 & -67.2 & -57.1 & -34.0 \\
\hline & Zhulongguan & 173.3 & 707.5 & 244.1 & 114.4 & 252.1 & 294.0 \\
\hline \multirow[t]{4}{*}{ JJA } & Fenglehe & 26.4 & -14.5 & 2.9 & -28.5 & 60.4 & 21.2 \\
\hline & Hongshahe & 23.0 & -7.4 & 17.1 & 24.6 & -5.5 & 18.8 \\
\hline & Zhulongguan & 42.5 & -44.9 & 17.1 & 31.3 & 35.2 & 60.3 \\
\hline & & & & & & & \\
\hline \multirow[t]{3}{*}{ DJF } & Fenglehe & 0.23 & 0.06 & 0.02 & 0.41 & 0.43 & 0.45 \\
\hline & Hongshahe & 0.22 & 0.04 & 0.03 & 0.47 & 0.45 & 0.41 \\
\hline & Zhulongguan & 0.09 & 0.15 & 0.07 & 0.22 & 0.19 & 0.15 \\
\hline \multirow[t]{4}{*}{ JJA } & Fenglehe & 0.68 & 0.68 & 0.70 & 0.87 & 1.00 & 0.95 \\
\hline & Hongshahe & 0.76 & 0.76 & 0.78 & 0.93 & 0.93 & 0.96 \\
\hline & Zhulongguan & 0.75 & 0.57 & 0.62 & 0.77 & 1.00 & 0.96 \\
\hline & & & & & & & \\
\hline \multirow[t]{3}{*}{ DJF } & Fenglehe & 0.72 & 0.92 & 0.95 & 0.51 & 0.61 & 0.65 \\
\hline & Hongshahe & 0.78 & 0.95 & 0.93 & 0.63 & 0.65 & 0.76 \\
\hline & Zhulongguan & 0.96 & 0.96 & 0.98 & 0.94 & 0.97 & 0.97 \\
\hline \multirow[t]{4}{*}{ JJA } & Fenglehe & 0.54 & 0.57 & 0.56 & 0.59 & 0.73 & 0.68 \\
\hline & Hongshahe & 0.69 & 0.68 & 0.68 & 0.66 & 0.68 & 0.69 \\
\hline & Zhulongguan & 0.70 & 0.66 & 0.67 & 0.68 & 0.73 & 0.72 \\
\hline & & & & & & & \\
\hline \multirow[t]{3}{*}{ DJF } & Fenglehe & 0.14 & 0.03 & 0.02 & 0.29 & 0.26 & 0.24 \\
\hline & Hongshahe & 0.12 & 0.02 & 0.02 & 0.26 & 0.25 & 0.18 \\
\hline & Zhulongguan & 0.03 & 0.03 & 0.02 & 0.05 & 0.03 & 0.03 \\
\hline \multirow[t]{3}{*}{ JJA } & Fenglehe & 0.38 & 0.36 & 0.37 & 0.38 & 0.27 & 0.31 \\
\hline & Hongshahe & 0.28 & 0.29 & 0.29 & 0.33 & 0.31 & 0.30 \\
\hline & Zhulongguan & 0.27 & 0.27 & 0.27 & 0.29 & 0.27 & 0.28 \\
\hline
\end{tabular}

An additional comparison is conducted at three independent hydrological stations and the nearest neighboring grid cells to verify how HRPP estimates relate to a single gauge reference (Table 5). These stations are all over the upper reaches with locations more than $0.5^{\circ}$ away from the nearest meteorological gauges. All the HRPPs underestimate winter precipitation amounts at the low-elevation Fenglehe and Hongshahe stations and considerably overestimate rainfall amounts with an RE of more than $100 \%$ at the high-altitude Zhulongguan. The NRMSE results also indicate that all products are less accurate at the Zhulongguan station than at the other two stations. The large station-to-station variability in RE and NRMSE may be associated with the local topographical features near gauge locations. Among all the considered products, APHRO and ITPCAS present better statistic results overall and a possible reason for the good performance of APHRO is the interpolation method considering topographical effects. The RE and NRMSE of all datasets appear lower in summer than winter. The underestimation of CMORPH-RAW is canceled by the gauge adjustment algorithms during summer, and CMORPH-CRT presents an RE below $18 \%$ at the three validation gauges, which makes the performance of CMORPH-CRT comparable to that of TRMM.

As shown in Fig. 4, the Taylor diagram (Taylor 2001) offers a concise summary of the degree of correspondence between the estimated and observed climatology by considering three statistics: the spatial correlation $r$, RMSE, and ratio of the standard deviations in a single diagram. Figure $4 \mathrm{c}$ shows that the HRPPs exhibit significant seasonality in precision at the independent hydrological stations. All products tend to underestimate the spatial variability of seasonal precipitation. The 
(a) Meteorological stations

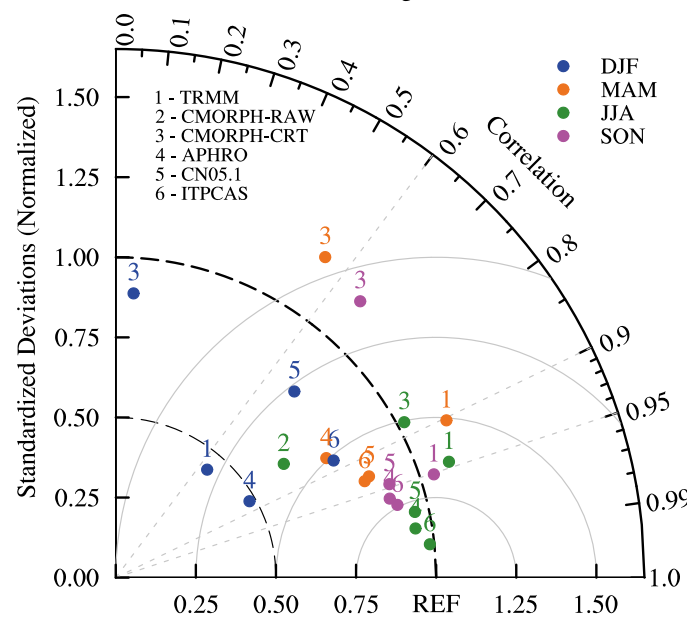

(b) Hydrological stations

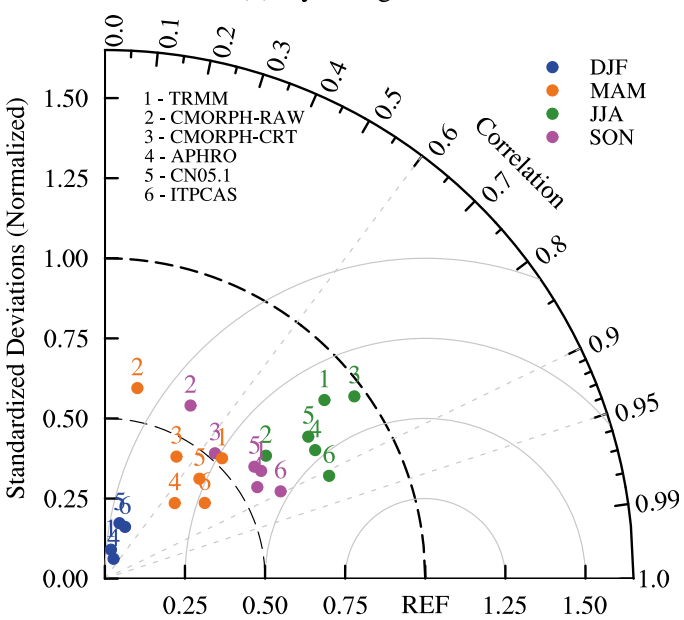

(c) Hydrological stations (radius $=0.3$ )

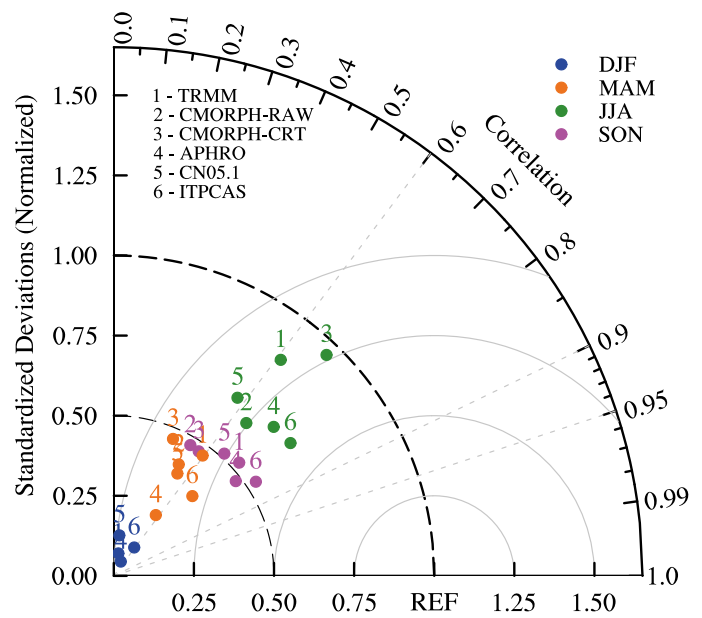

FIG. 4. Taylor diagram of seasonal mean precipitation climatology between the HRPPs and observations for the (a) meteorological stations, (b) all hydrological stations, and (c) independent hydrological stations over the HRB.

estimated spatial patterns of precipitation are better in summer than those in the other three seasons. In winter, the HRPPs show limited consistency with in situ measurements and present spatial correlation coefficients mostly smaller than 0.6; the two CMORPH products, in particular, give unrealistic $r$ values below 0 . The ratio of the standard deviation is less than 0.25 , indicating that the products are not accurate and exhibit less variability than surface observations. ITPCAS and APHRO perform best with lower RMSE values and higher $r$ values in all seasons, and they are slightly superior to CN05.1. Although the bias-correction process in CMORPHCRT improves the consistency with observations than its corresponding satellite-only product, CMORPHCRT shows poor performance when compared with other products in all seasons except summer. Similar conclusions could be drawn when considering only the meteorological stations, although a dependency problem exists between meteorological records and HRPPs. The two CMORPH products show weaker spatial correlations and larger RMSEs than the other products, which is consistent with the results at independent stations. The results indicate that the bias-correction processes in CMORPHCRT fail to reduce the errors significantly, although they exhibit improvements in higher spatial correlations and smaller RMSEs to some extent. The results at all hydrological stations are similar to those at independent stations, but are more consistent with observations because of the influence of meteorological gauges nearby.

\section{b. Interannual variability and the seasonal cycle}

The HRB is dominated by large interannual variability in areas that present low precipitation. To further examine the capability of the HRPPs in depicting the temporal variability of precipitation, the interannual variations of seasonal precipitation are analyzed. The 
(a) DJF

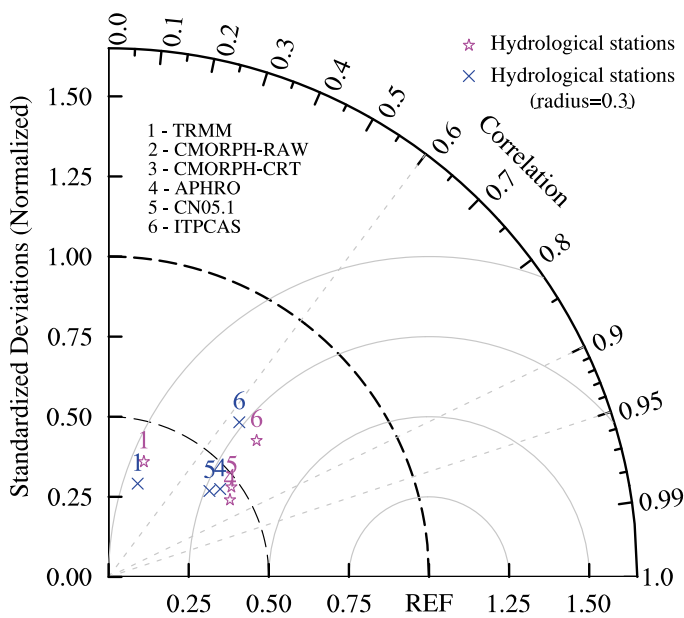

(c) JJA

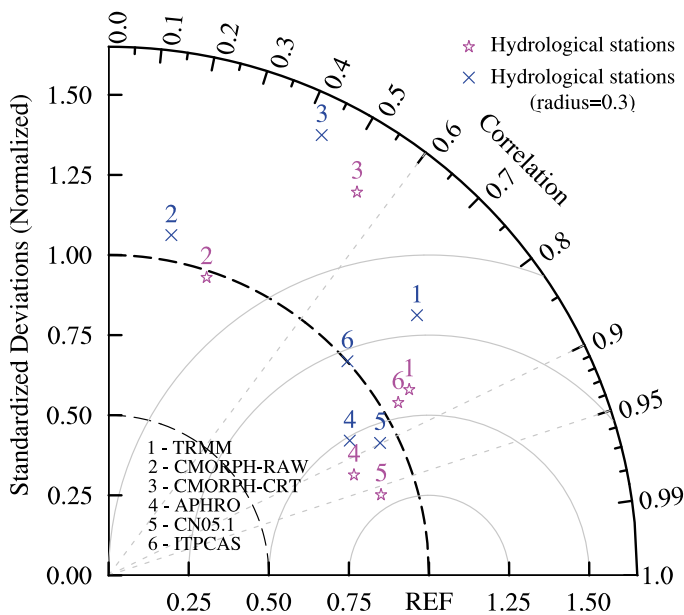

(b) MAM

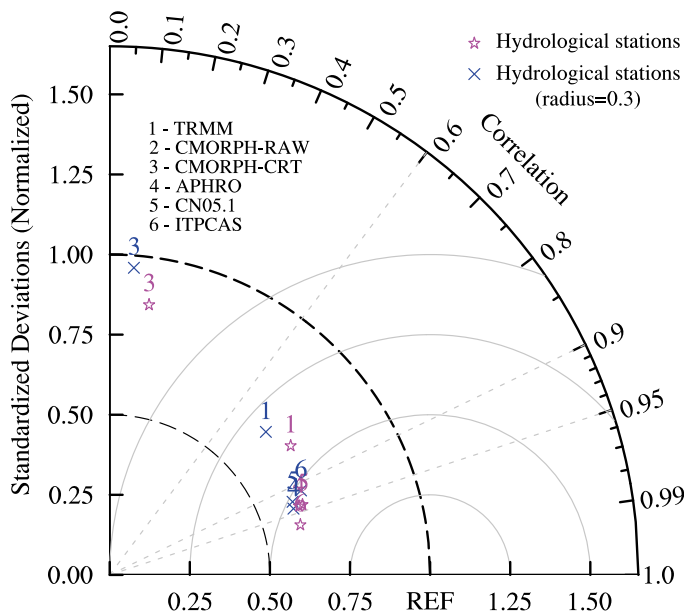

(d) SON

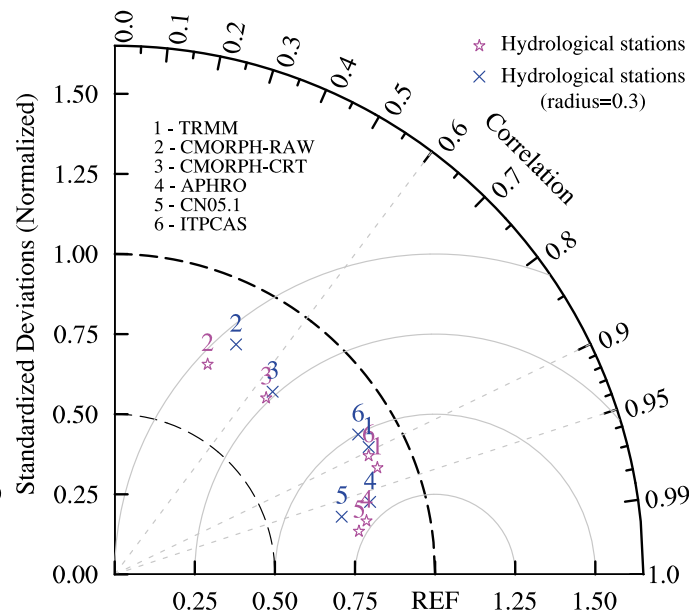

FIG. 5. Taylor diagram for the interannual variability of seasonal precipitation between the high-resolution products and observations.

Taylor diagram for interannual variability of seasonal precipitation at hydrological stations is shown in Fig. 5. Focusing on the independent hydrological gauges in winter, the gauge-based HRPPs show high temporal correlations (above 0.6) and low RMSEs. TRMM shows a relatively poor performance with a correlation below 0.3, whereas the two CMORPH products cannot capture the interannual variability of winter precipitation over the HRB. All HRPPs, especially TRMM, underestimate this variability. In summer, the temporal correlations between the HRPPs and observations are slightly improved, and most of the correlations range from 0.7 to 0.9 , except for that of CMORPH-RAW and CMORPH-CRT. The gauge-based HRPPs outperform the satellite-based HRPPs in reproducing the interannual variability of summer precipitation, which may be related to the inclusion of more gauge records in the products and the indirect measurements of satellite-based data. Compared with the results in winter, the two CMORPH products and TRMM tend to overestimate the summer precipitation interannual variability. CMORPH-CRT demonstrates a minor improvement when compared with CMORPH-RAW in terms of correlations and RMSEs. Except for the two CMORPH products, the scatter points from the HRPPs are more concentrated and closer to the reference point, and they present high correlations ranging from 0.8 to 0.99 in spring and autumn, which indicates a better skill of HRPPs in reproducing the interannual variability of seasonal precipitation in these two seasons. When considering all hydrological stations, the results share certain common characteristics with those of independent data; however, all HRPPs present relatively better performance due to the spatial coherence of neighboring meteorological stations. To ensure the reliability of the validation results, HRPPs are evaluated against 

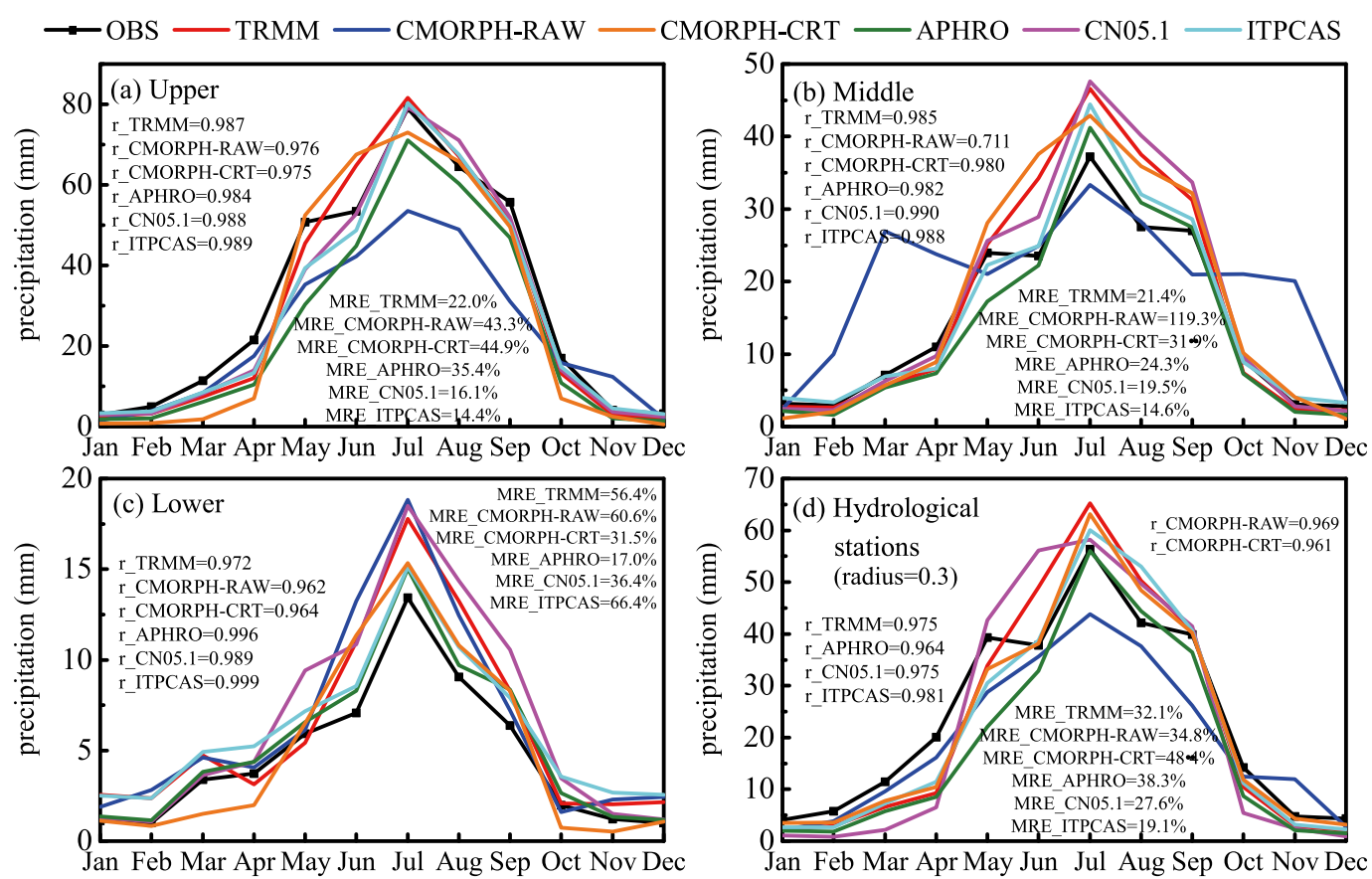

FIG. 6. Seasonal variation of precipitation produced by the HRPPs and observations over the (a) upper, (b) middle, and (c) lower reaches and (d) at independent hydrological stations. The statistics are calculated for the different subregions.

independent hydrological gauges that are far away from meteorological stations.

Generally, the gauge-based HRPPs can accurately describe the interannual variability of the observed seasonal precipitation and exhibit a better performance than the satellite-derived products. CN05.1 is the most consistent with surface observations, and APHRO and ITPCAS provide favorable results over the HRB, which are also reflected in the results over different subregions (figures not shown). However, the two CMORPH products fail to capture the temporal pattern of the seasonal precipitation and present correlations that are mostly below 0.6 and even negative in winter. Compared with CMORPH-CRT, TRMM is more consistent with gauge data, which may be related to the combination of rainfall estimates derived from IR data and the better bias-correction algorithms in the TRMM product. A similar finding for the Urmia basin of Iran is also reported by Ghajarnia et al. (2015), who found that at an annual time scale, TRMM 3B42 exhibits better results than CMORPH-CRT and presents much lower RMSEs and higher correlations with the observations.

Figure 6 shows the annual cycle of precipitation at different subregions based on various precipitation datasets. The observed precipitation over the basin is concentrated from June to September and peaks in July, whereas it reaches the minimum in winter, especially in the downstream area. At the independent hydrological stations, the HRPPs can portray the seasonal cycles of precipitation well, with high correlations above 0.95 and low MREs (Fig. 6d), although they overestimate the precipitation amounts during the warm season (from June to September) except for CMORPH-RAW, which underestimates the precipitation from April to September and overestimates the precipitation in November. The gauge-adjusted CMORPH effectively improves the quality of original satellite estimates but exhibits considerable underestimation for winter precipitation. ITPCAS performs best in terms of $r$ and MRE values, and it is followed by CN05.1, although both products yield high overestimations in the warm season and CN05.1 considerably underestimates the precipitation in winter. Despite the possible dependency problem, over the upper and middle reaches, all products except for CMORPH-RAW still overestimate the observed rainfall during the warm season and underestimate it in winter, but to a lesser degree than with independent data. However, the satelliteonly CMORPH cannot capture the seasonal cycle over the middle reaches, and it displays three peaks in March, July, and November. The bias correction procedures applied in CMORPH-CRT contribute to the satisfactory precision over the middle reaches, although this product yields relatively higher MRE than other HRPPs. Overall, except for the CMORPH-RAW over the middle reaches, the HRPPs can reasonably represent the unimodal characteristics of the annual cycle of precipitation over the HRB. 
TABLE 6. Daily and monthly comparison of rain gauge and HRPPs at the three hydrological stations. Bold font indicates the best statistical metrics among six products.

\begin{tabular}{|c|c|c|c|c|c|c|c|}
\hline Time & Station & TRMM & CMORPH-RAW & CMORPH-CRT & APHRO & CN05.1 & ITPCAS \\
\hline \multicolumn{8}{|c|}{$r$} \\
\hline \multirow[t]{3}{*}{ Daily } & Fenglehe & 0.399 & 0.236 & 0.285 & 0.528 & 0.447 & 0.455 \\
\hline & Hongshahe & 0.367 & 0.237 & 0.245 & 0.436 & 0.458 & 0.387 \\
\hline & Zhulongguan & 0.249 & 0.209 & 0.270 & 0.276 & 0.272 & 0.284 \\
\hline \multirow[t]{3}{*}{ Monthly } & Fenglehe & 0.690 & 0.359 & 0.537 & 0.821 & 0.722 & 0.734 \\
\hline & Hongshahe & 0.810 & 0.500 & 0.578 & 0.765 & 0.797 & 0.762 \\
\hline & Zhulongguan & 0.803 & 0.487 & 0.703 & 0.825 & 0.825 & 0.790 \\
\hline \multicolumn{8}{|c|}{ NRMSE } \\
\hline \multirow[t]{3}{*}{ Daily } & Fenglehe & 4.10 & 4.24 & 4.28 & 3.51 & 3.70 & 3.64 \\
\hline & Hongshahe & 3.82 & 4.14 & 4.58 & 3.54 & 3.41 & 3.64 \\
\hline & Zhulongguan & 5.55 & 4.62 & 6.01 & 4.76 & 4.37 & 5.25 \\
\hline \multirow[t]{3}{*}{ Monthly } & Fenglehe & 0.83 & 1.08 & 1.00 & 0.79 & 0.85 & 0.74 \\
\hline & Hongshahe & 0.66 & 1.02 & 1.19 & 0.73 & 0.67 & 0.74 \\
\hline & Zhulongguan & 1.30 & 1.34 & 1.54 & 1.09 & 1.14 & 1.71 \\
\hline \multicolumn{8}{|c|}{$\operatorname{RE}(\%)$} \\
\hline \multirow[t]{3}{*}{ Daily } & Fenglehe & -10.5 & -16.5 & -20.7 & -44.8 & 13.0 & -7.9 \\
\hline & Hongshahe & 0.5 & 7.2 & 15.2 & -4.7 & -22.5 & 6.3 \\
\hline & Zhulongguan & 67.3 & -2.1 & 52.3 & 47.3 & 63.7 & 91.3 \\
\hline \multirow[t]{3}{*}{ Monthly } & Fenglehe & -10.5 & -16.5 & -20.7 & -44.8 & 13.0 & -7.9 \\
\hline & Hongshahe & 0.5 & 7.2 & 15.2 & -4.7 & -22.5 & 6.3 \\
\hline & Zhulongguan & 67.3 & -2.1 & 52.3 & 47.3 & 63.7 & 91.3 \\
\hline
\end{tabular}

Table 6 lists the daily and monthly comparison statistics for HRPPs at the three independent hydrological stations. As expected, the accuracy of all products with respect to temporal correlation, NRMSE, and RE improves with increasing temporal scale. The gaugebased products, especially ITPCAS, present good skill in capturing variations of monthly precipitation at independent gauges. TRMM presents lower NRMSE and $\mathrm{RE}$ and higher $r$ than the two CMORPH products and is comparable to gauge-based HRPPs. A possible reason for the good performance of TRMM at monthly time scales is that this product is constrained by GPCC monthly gauge analysis. CMORPH-CRT performance is superior compared to satellite-only data in terms of temporal correlation; however, it generates larger RE than CMORPH-RAW.

\section{c. Daily precipitation}

Comparison of daily precipitation between the three independent hydrological stations and the nearest pixels indicates deteriorated accuracy of HRPPs compared to the monthly scale (Table 6). Consistent with the results of monthly analysis, TRMM outperforms the two CMORPH products in terms of temporal correlation and RE at the daily time scale. CMORPH-CRT presents higher correlation with observations as compared to its satellite-only product, but the improvement in NRMSE and RE is not obvious after gauge adjustment. The gauge-based HRPPs exhibit better consistence with daily gauge observations than satellite-based ones. With respect to the skill of detecting rainfall occurrences, the performance of all products tends to be better in summer than in winter (Table 5). The seasonal variation of detection statistics is more significant for satellite-based HRPPs, especially for CMORPH-RAW and CMORPHCRT, which consistently generate worse scores (low POD and CSI and high FAR) than other products in winter and can capture the rain events well in summer. The poor performance of satellite products during winter may be attributed to the miss of low-intensity precipitation in gauges and the poor capacity of the PMW retrievals in the identification of cold season precipitation (Xie et al. 2017). The adjustment procedures of CMORPH-CRT have little improvement in daily rainfall detection, which is consistent with the findings of Guo et al. (2015). The gauge-based HRPPs are more skillful than satellite-based products in the POD score at both seasons, but the reverse is true for FAR values generated by CN05.1 and ITPCAS in summer, indicating an overprediction problem of gauge-based products during summer. One source of the high false alarm ratios for all products is the different spatial representativeness of HRPPs and gauges. The HRPPs represent areal average rainfall over grid boxes in which more precipitation events are expected to occur compared to the point rain gauges (Satgé et al. 2016; Hussain et al. 2017).

Accurate descriptions of precipitation frequency at various intensities are critical for studying hydrological 
(a) DJF
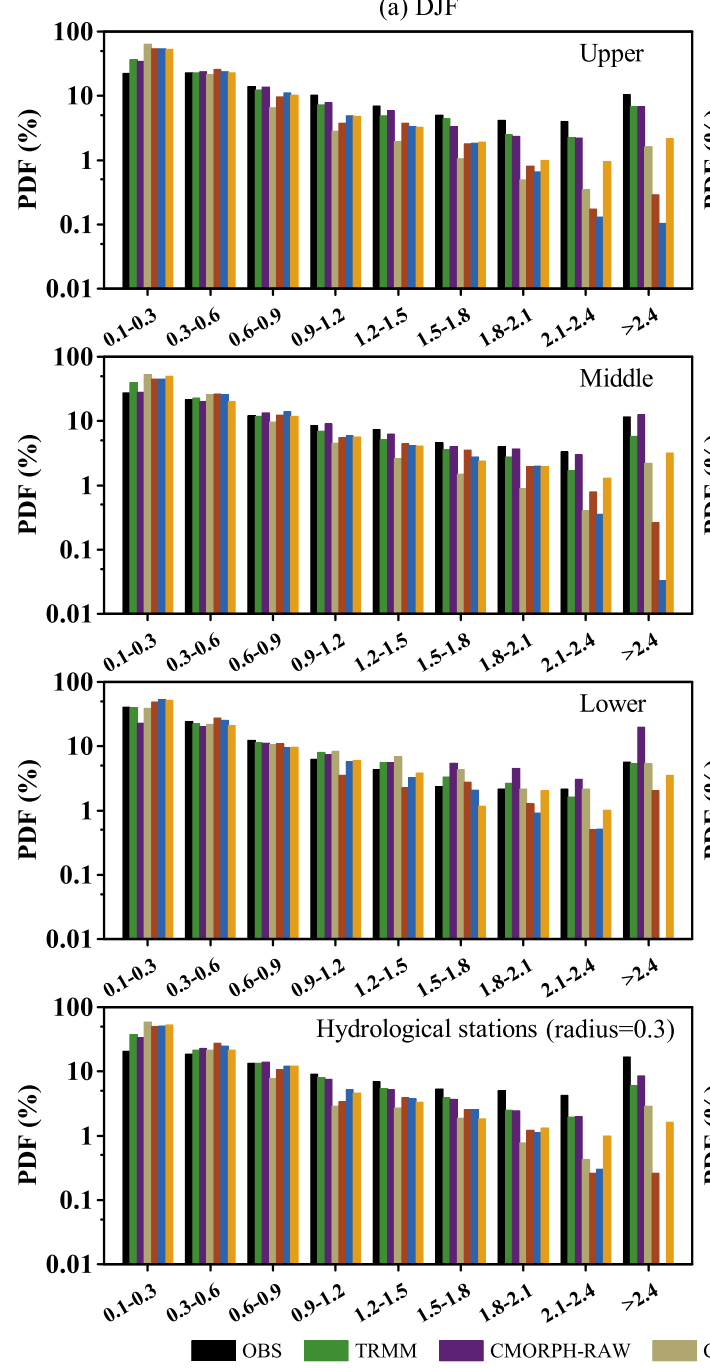

(b) JJA
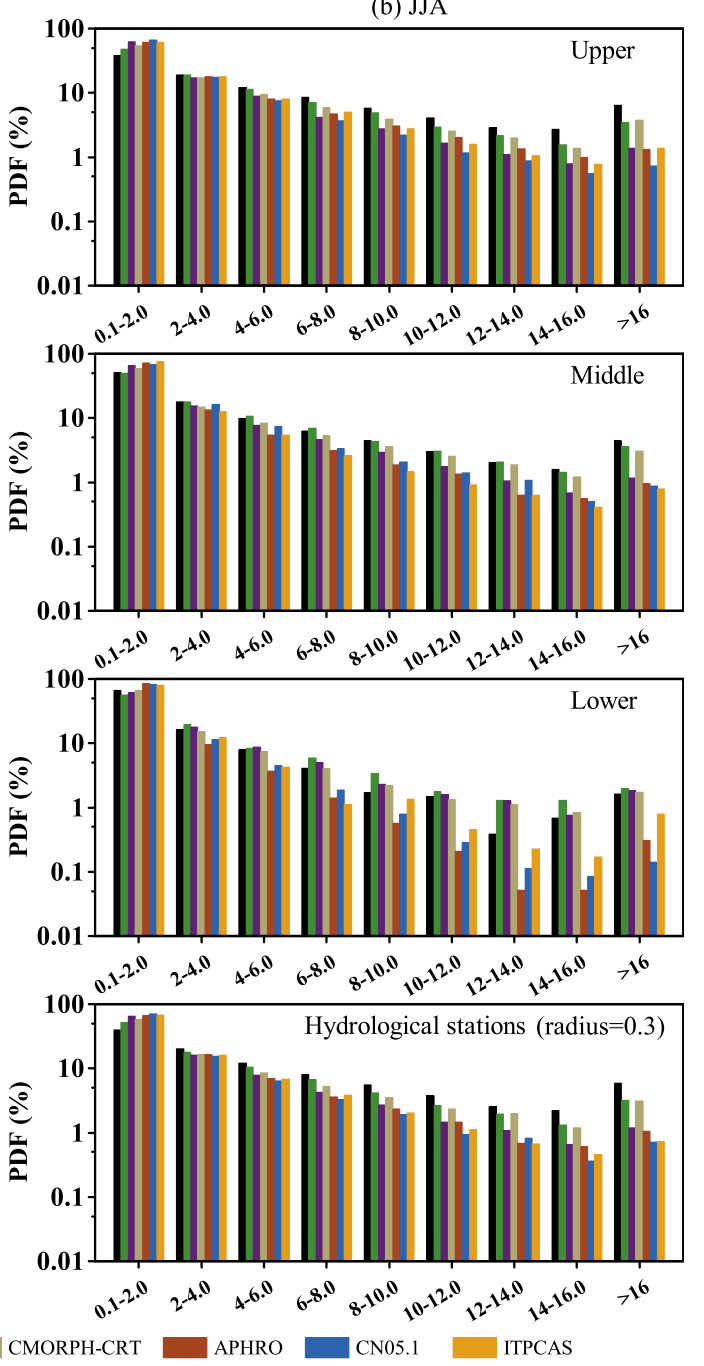

FIG. 7. PDFs of the daily precipitation for different subregions over the HRB in (a) winter and (b) summer.

processes, performing climate predictions, and evaluating land-atmosphere interactions. The probability distribution provides unique insights into the systematic bias related to precipitation rates, thus revealing the hidden errors of the results at seasonal or longer time scales (Sun et al. 2006; Perkins et al. 2007). Figure 7 illustrates the observed and estimated PDFs for daily precipitation, and the intensity is divided into nine categories in both summer and winter. Only daily precipitation above $0.1 \mathrm{mmday}^{-1}$ is used to generate PDFs. In general, all datasets are consistent with the observed PDFs, although they tend to overestimate or underestimate the observed values at certain intensities. In all substreams and at the hydrological stations, the intensities of most of the precipitation events are less than $0.3 \mathrm{~mm} \mathrm{day}^{-1}$ in winter and $2 \mathrm{~mm} \mathrm{day}^{-1}$ in summer. In winter, the frequency of daily rainfall below $0.3 \mathrm{~mm}^{-1 a y}{ }^{-1}$, which is above $20 \%$ according to the observations, is considerably overestimated by all products over the whole basin, except for satellite-based datasets over the lower reaches. The gauge-derived HRPPs show dramatic overestimation at $0.1-0.3 \mathrm{~mm}^{-1 a y}{ }^{-1}$ by around $30 \%$ at hydrological stations, and CMORPH-CRT captures too many light rain events than ground truth by $38 \%$ and presents more overestimation than its corresponding original satellite estimates. The maximum precipitation rate is the highest in the upstream areas and lowest in the downstream areas in summer. The HRPPs can accurately reproduce the PDF of daily precipitation, whereas the gauge-based products tend to underestimate the PDF for intensities above $4 \mathrm{~mm}_{\text {day }}{ }^{-1}$, especially over the lower reaches. The bias-correction procedures applied in CMORPH-CRT reduce the magnitude of overestimation and underestimation of light rain $\left(0.1-2 \mathrm{~mm} \mathrm{day}^{-1}\right)$ significantly as compared to CMORPH-RAW in summer. 
(a) DJF

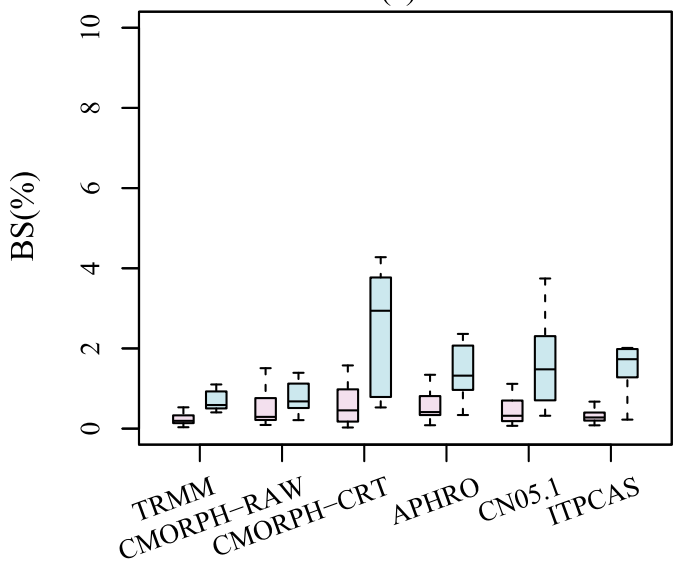

(c) DJF

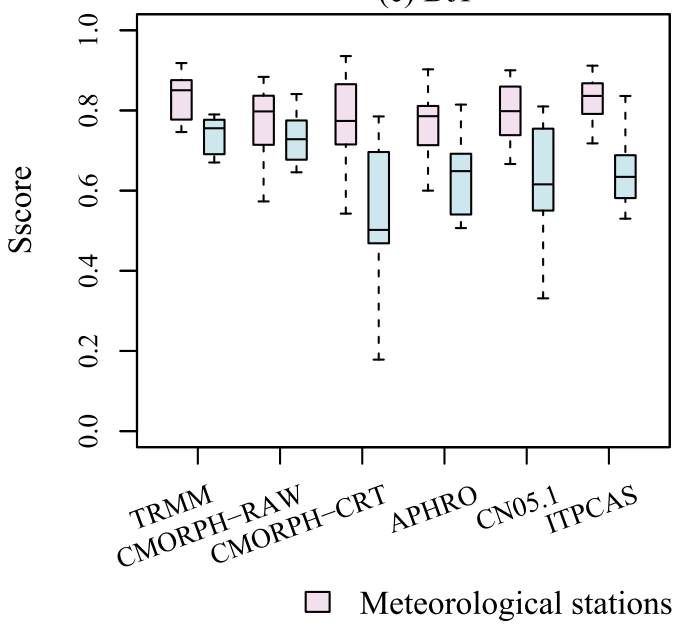

(b) JJA

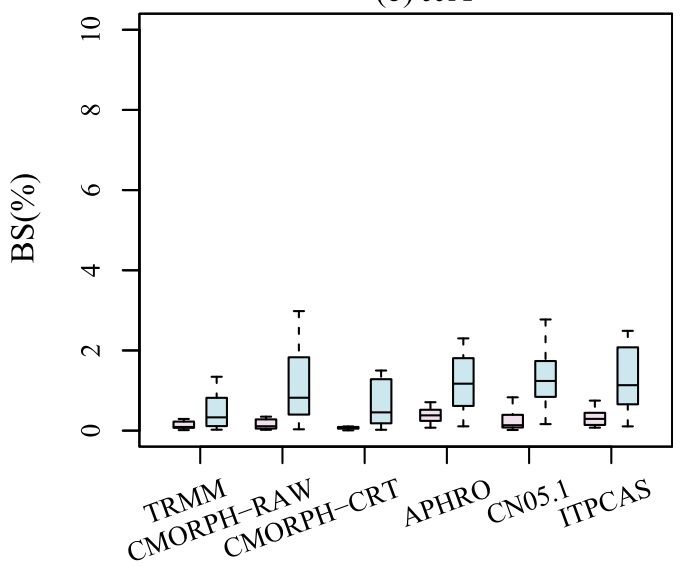

(d) JJA

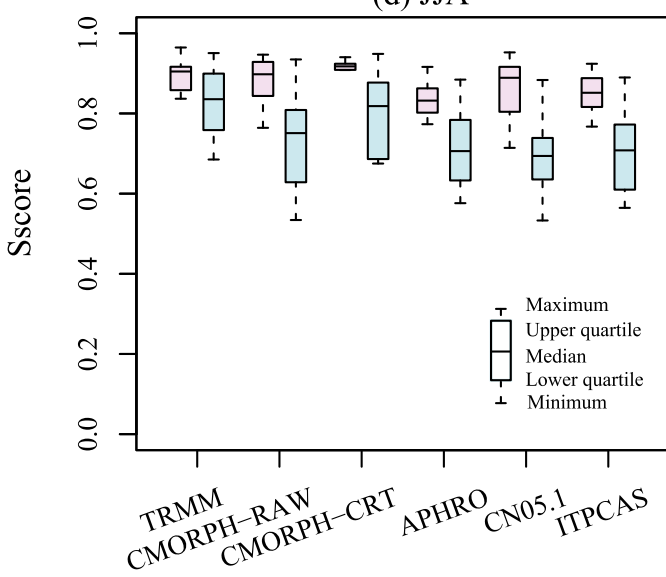

Hydrological stations (radius $=0.3$ )

FIG. 8. Box plots of the PDF-based BS and $S_{\text {score }}$ values for the daily precipitation across all stations. The BS and $S_{\text {score }}$ are considered to be perfect at 0 and 1 , respectively.

To quantify the accuracy of the HRPPs, two PDFbased statistics, BS and $S_{\text {score }}$, are calculated at each station. A small BS together with a large $S_{\text {score }}$ represents increased consistency between the observed and estimated PDFs. As demonstrated in Fig. 8, all products can reasonably reproduce the probability distribution, although the indices at the hydrological stations show a greater degree of dispersion because they are not used to generate or calibrate HRPPs. In winter, TRMM and CMORPH-RAW accurately reproduce the PDF of independent observed precipitation, and the median BS is lower than $1 \%$ and the $S_{\text {score }}$ is greater than 0.7 . Although all products present similar good scores at meteorological stations, the accuracy of gauge-based HRPPs is acceptable but relatively weak at independent observations. Similarly, during summer, all products present substantial variations at the hydrological stations, indicating great spatial variability in the scores. The results at two station groups indicate that TRMM and CMORPH-CRT exhibit a greater ability to depict the probability distribution in summer, whereas APHRO and ITPCAS show a similar ability regardless of the season. CMORPH-CRT shows substantial improvement compared to CMORPH-RAW in terms of BS and $S_{\text {score }}$ during summer, possibly because of the bias-correction based on the PDF matching technique. However, CMORPH-CRT performs even worse than its original satellite product in winter with a higher overestimation of light rain and worse PDF-based statistics, which may be related to the false detection and missed events (high FAR and low POD) during the cold season.

\section{d. Extreme precipitation}

In recent years, extreme precipitation events have received increasing attention because of their social and ecological impacts. We evaluate the HRPPs with respect to their ability to depict the regional characteristics of precipitation extremes. Figure 9 reveals the spatial pattern 


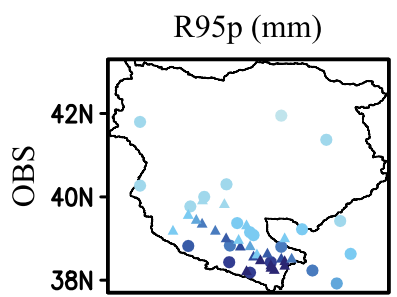

PRCPTOT (mm)
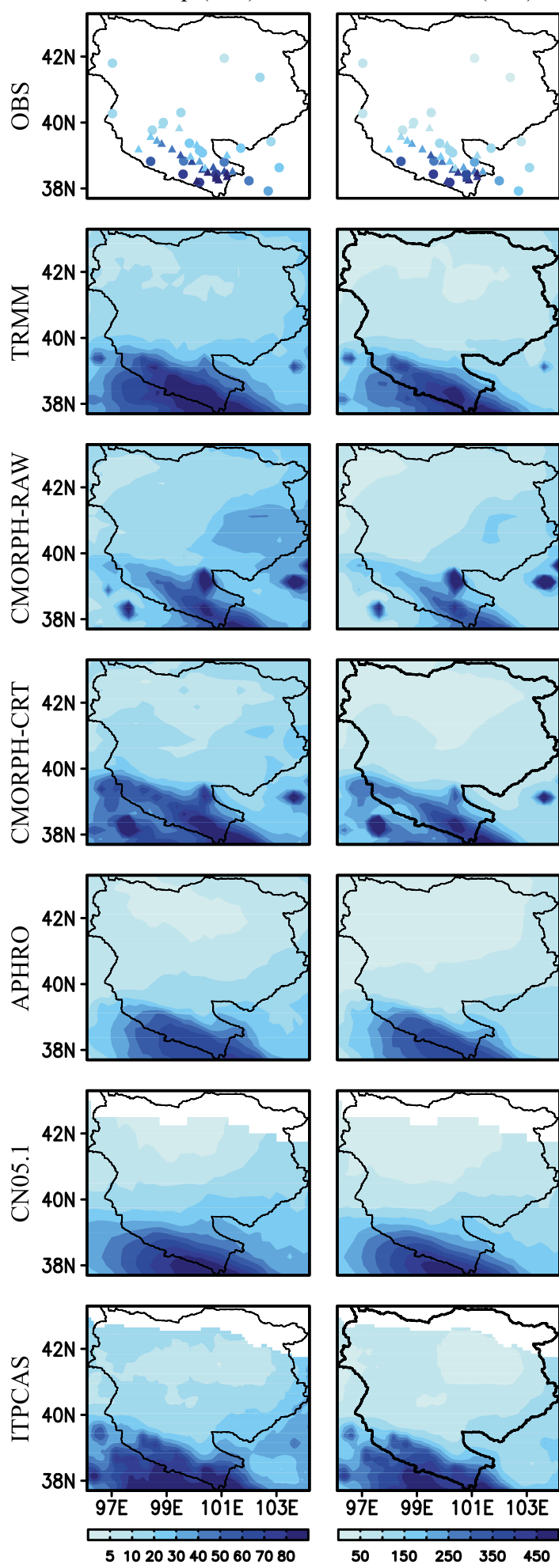
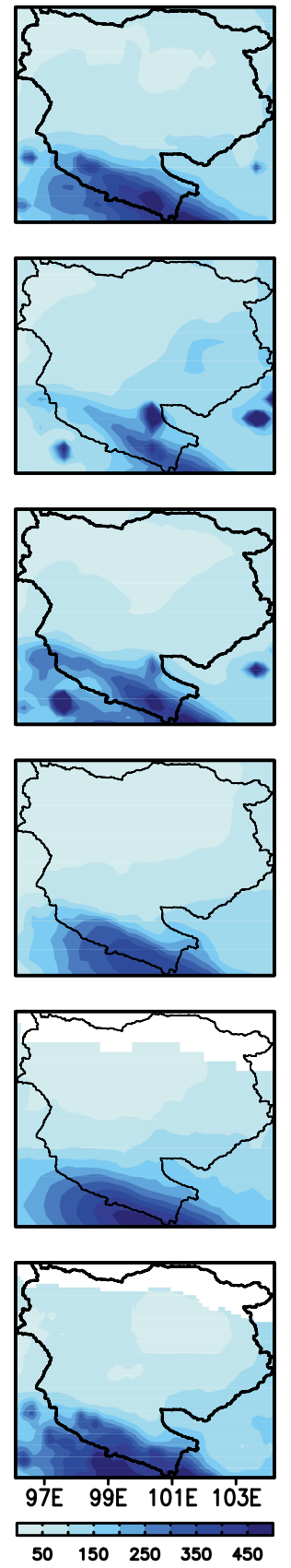

Rx1d (mm)
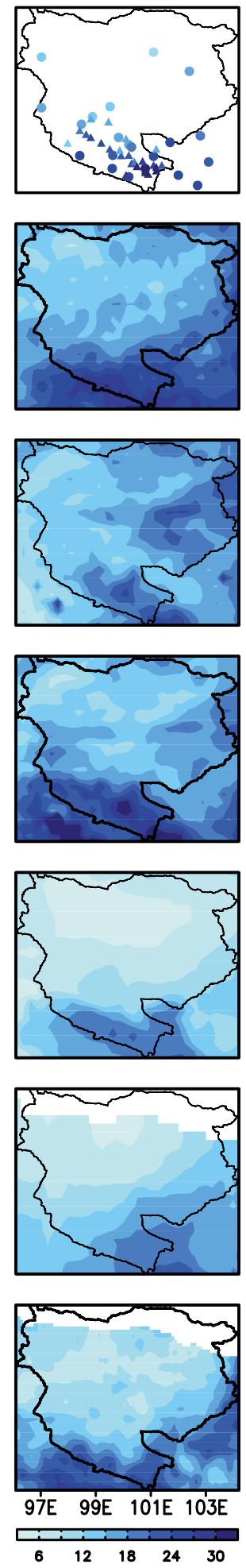

$\mathrm{Rx} 5 \mathrm{~d}(\mathrm{~mm})$
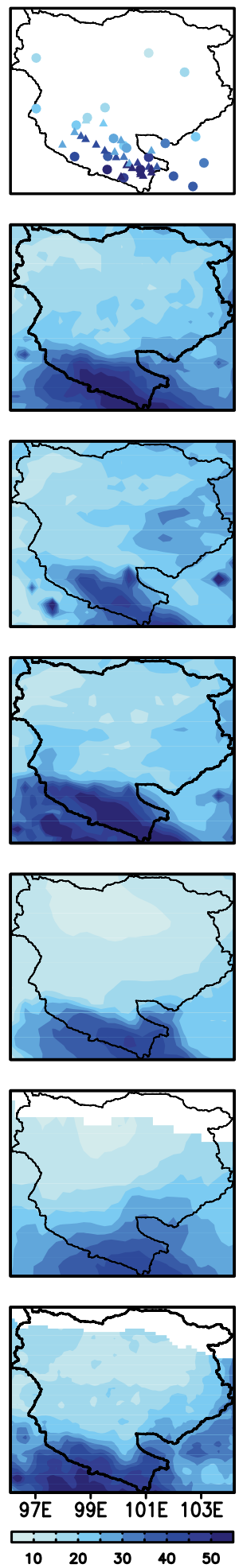

FIG. 9. Spatial distribution of the extreme indices (related to precipitation amount) produced by the observations and HRPPs. 
TABLE 7. Statistics (MRE, RMSE, and spatial correlation) for the extreme precipitation indices between the HRPPs and observations. Bold font indicates the best statistical merits among products.

\begin{tabular}{|c|c|c|c|c|c|c|c|c|c|}
\hline Products & Statistics & $\mathrm{CDD}$ & CWD & R10 & SDII & R95p & PRCPTOT & Rx1d & $\mathrm{Rx} 5 \mathrm{~d}$ \\
\hline \multirow[t]{3}{*}{ TRMM } & MRE & 24.98 & 21.48 & 40.96 & 12.21 & 34.35 & 31.13 & 15.40 & 18.25 \\
\hline & RMSE & 18.86 & 1.90 & 2.98 & 0.88 & 18.26 & 79.20 & 4.69 & 9.91 \\
\hline & $r$ & 0.78 & 0.74 & 0.79 & 0.53 & 0.78 & 0.84 & 0.71 & 0.74 \\
\hline \multirow[t]{3}{*}{ CMORPH-RAW } & MRE & 29.81 & 66.46 & 56.81 & 28.38 & 52.56 & 54.96 & 25.63 & 26.85 \\
\hline & RMSE & 25.78 & 6.22 & 5.07 & 1.81 & 26.25 & 136.54 & 7.69 & 13.81 \\
\hline & $r$ & 0.50 & 0.09 & 0.47 & -0.04 & 0.47 & 0.44 & 0.46 & 0.59 \\
\hline \multirow[t]{3}{*}{ CMORPH-CRT } & MRE & 67.76 & 32.55 & 41.67 & 14.59 & 38.83 & 32.09 & 19.18 & 22.43 \\
\hline & RMSE & 39.90 & 2.35 & 2.87 & 0.90 & 20.24 & 86.66 & 5.65 & 10.87 \\
\hline & $\mathrm{r}$ & 0.37 & 0.66 & 0.82 & 0.45 & 0.71 & 0.80 & 0.58 & 0.69 \\
\hline \multirow{3}{*}{ APHRO } & MRE & 32.51 & 23.01 & 50.45 & 28.70 & 31.67 & 23.87 & 29.57 & 21.95 \\
\hline & RMSE & 20.86 & 1.04 & 4.46 & 1.71 & 22.29 & 94.47 & 7.84 & 10.78 \\
\hline & $r$ & 0.73 & 0.87 & 0.77 & 0.65 & 0.84 & 0.85 & 0.79 & 0.86 \\
\hline \multirow[t]{3}{*}{ CN05.1 } & MRE & 28.88 & 64.08 & 46.74 & 30.97 & 25.20 & 27.07 & 28.70 & 20.88 \\
\hline & RMSE & 19.02 & 5.13 & 4.49 & 1.84 & 17.47 & 82.17 & 8.17 & 11.57 \\
\hline & $r$ & 0.72 & 0.74 & 0.76 & 0.48 & 0.82 & 0.85 & 0.75 & 0.82 \\
\hline \multirow[t]{3}{*}{ ITPCAS } & MRE & 27.39 & 25.60 & 39.82 & 23.71 & 20.30 & 16.48 & 20.80 & 15.47 \\
\hline & RMSE & 17.94 & 1.54 & 4.37 & 1.56 & 14.28 & 73.16 & 6.25 & 9.17 \\
\hline & $r$ & 0.80 & 0.81 & 0.78 & 0.47 & 0.90 & 0.91 & 0.79 & 0.86 \\
\hline
\end{tabular}

of extreme indices related to precipitation amount (R95p, PRCPTOT, Rx1d, and Rx5d) derived from the HRPPs and rain gauge observations, and associated statistics are listed in Table 7. For R95p and PRCPTOT, the spatial distributions are similar to those of annual precipitation, with the indices decreasing gradually from south to north and showing a maximum above $80 \mathrm{~mm}$ for R95p and $450 \mathrm{~mm}$ for PRCPTOT over the upper reaches. Except for CMORPH-RAW, the HRPPs are able to accurately reproduce the pattern of the observed R95p and PRCPTOT and present spatial correlations above 0.7 (significant at the $95 \%$ confidence level) and relatively low RMSEs (Table 7). TRMM and the two CMORPH products tend to overestimate the R95p over the middle and lower reaches, whereas CMORPH-RAW distinctly overestimates R95p and PRCPTOT over the eastern HRB, and CMORPHCRT improves this condition greatly. The performance of the HRPPs for Rx1d and Rx5d are similar to those for R95p and PRCPTOT: the RMSEs are all below $12 \mathrm{~mm}$ and the spatial correlations are all above 0.7, except for CMORPH-RAW and CMORPH-CRT. TRMM overestimates Rx1d and Rx5d over the HRB, whereas APHRO and CN05.1 tend to underestimate Rx1d. Compared with the other HRPPs, the two CMORPH products cannot accurately reproduce the spatial pattern of Rx1d and $\mathrm{Rx} 5 \mathrm{~d}$, and they significantly overestimate these indices over the lower reaches and the eastern part of the HRB, especially for Rx1d at correlations below 0.6. It is noted that uncertainties inherently arise from the comparison of gauge accumulations to the satellite snapshot data, which could be partially responsible for the relatively low correlation and large RMSE for satellite-based HRPPs.
The extreme indices related to the precipitation days (CDD, CWD, and R10) and intensity (SDII) are shown in Fig. 10. The main features of the climatological pattern of extreme precipitation events represented by the CDD are reasonably well captured by the HRPPs compared with the rain gauge observations, and the spatial correlations are larger than 0.7 , except for the CDD from two CMORPH products. For the CWD, the overestimation of the magnitude is located in the upper reaches for TRMM and two CMORPH products, and slight underestimations are observed for the products based on rain gauges. All the HRPPs overestimate the CWD in the upstream region, especially CN05.1 and ITPCAS, and CMORPH-CRT can accurately reproduce the spatial distribution of the CWD and presents an obvious improvement with an increasing correlation from 0.09 to 0.66 and a decreasing RMSE and MRE as compared to the satellite-only CMORPH. The south-north contrast in the HRB with higher R10 in the upstream region and lower values in the middle and lower reaches is reasonably well represented by the HRPPs: the RMSEs are all below 5 days and the correlations are all above 0.60 , except for CMORPH-RAW (Table 7). Moreover, CMORPH-RAW and CN05.1 tend to underestimate the R10 over the upper reaches; therefore, the RMSEs are larger than those of the other HRPPs. Compared with the other precipitation extreme indices, the SDII is relatively poorly reproduced by the HRPPs and presents relatively low correlations. Although most of the HRPPs can reveal the spatial pattern of the SDII, TRMM produces large positive biases over the eastern HRB and the lower reaches, whereas the 

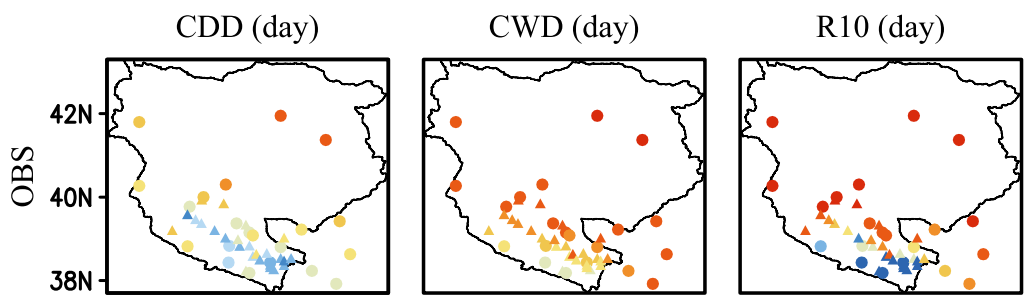

SDII (mm/day)
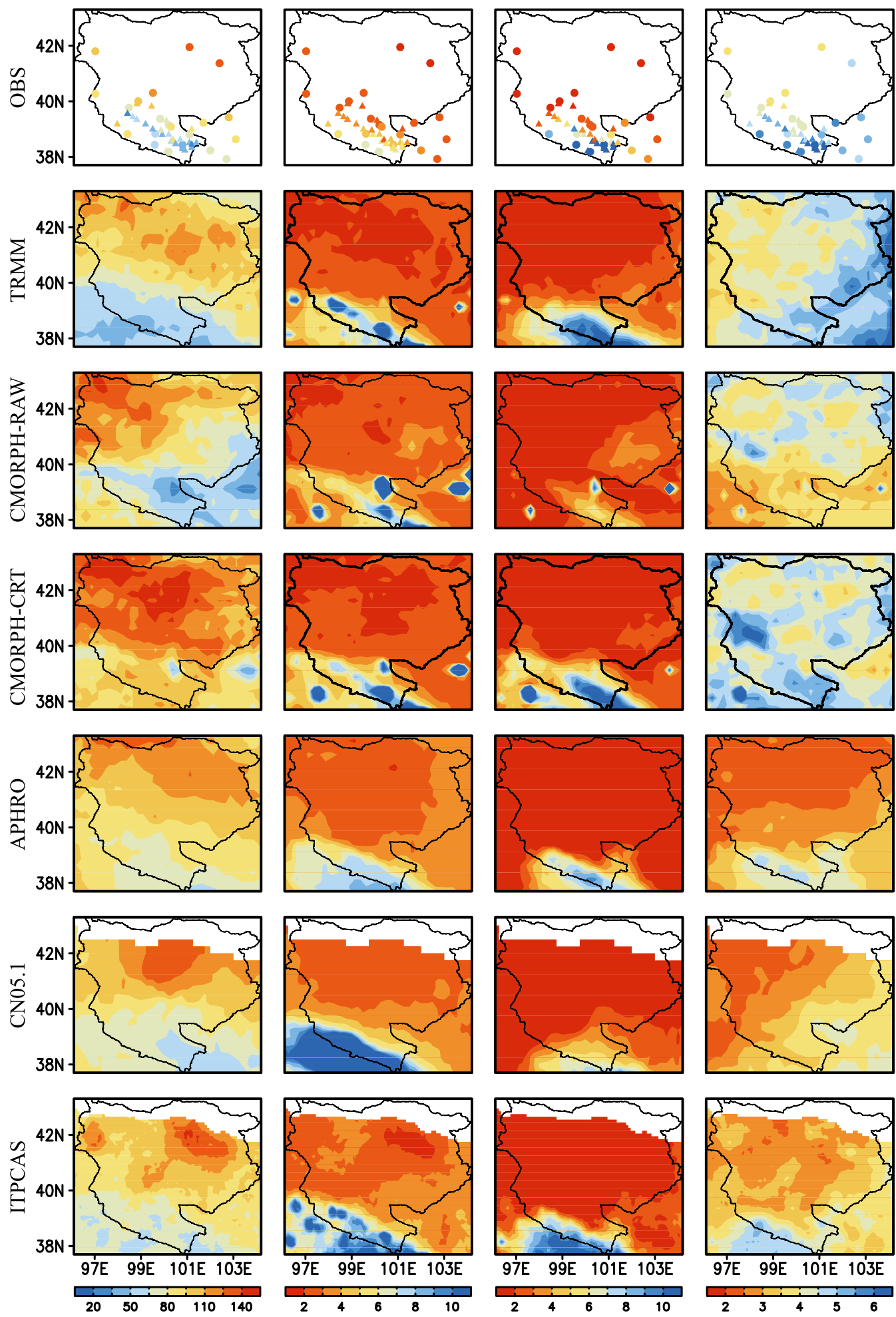

FIG. 10. As in Fig. 9, but for spatial distributions of the indices related to precipitation days (CDD, CWD, and R10) and intensity (SDII). 
gauge-based products tend to underestimate the SDII. However, CMORPH-RAW does not capture the main spatial characteristics, and it even shows an opposite pattern, with a correlation at -0.04 . The bias-correction procedure improves the quality of CMORPH-CRT in terms of statistical metrics, although the product still shows underestimation over the southeastern basin.

Figures 11 and 12 show the spatial patterns of linear trends of the eight extreme precipitation indices from 1998 to 2012. The gauge observations indicate that the observed CDD mainly shows a decreasing trend except for an increasing trend at the northeastern part of the lower reaches, whereas the trends for other extreme indices are mainly positive, indicating a wetting tendency from 1998 to 2012 over most parts of the HRB. However, most of these trends are nonsignificant over the HRB. The results for 1998-2007 (APHRO) and 1998-2010 (ITPCAS) are similar to those for the most recent 15 years and present the same direction of trends for all indices; however, the extents of the increases and decreases have been strengthened or weakened (figures not shown).

The HRPPs can generally reproduce the change trends observed in the rain gauge data, although there is a certain deviation of magnitude. Overall, the accuracy of the gauge-based data is higher than that of the satellite-derived products, and the estimated trends for SDII, Rx1d, and Rx5d are relatively better and present smaller RMSEs and higher spatial correlation coefficients (greater than 0.4) for CN05.1 and ITPCAS. APHRO and ITPCAS can accurately capture the locations of the major changes in the eight indices in the southern Qilian Mountains. The trends for R95p and PRCPTOT are reasonably represented by the HRPPs except for the two CMORPH products, which fail to reproduce the decadal trends of R95p and PRCPTOT and present negative spatial correlations. CN05.1 and TRMM show an increasing trend of R95p over the upper reaches of the HRB, which is inconsistent with the observations, and TRMM overestimates the increasing trends of R95p and PRCPTOT over the eastern HRB. For Rx1d and Rx5d, all the HRPPs are consistent with observations over the HRB and present small biases, and most of the spatial correlations are above 0.3 (significant at the $95 \%$ confidence level), especially in the downstream areas. However, the satellite-based HRPPs tend to overestimate the increasing trends over the eastern HRB. For the CDD, although the observed spatial trend is accurately reproduced by the gaugebased datasets, APHRO overestimates the negative trend of the CDD in the upstream. The satellite-derived products show limited accuracy and negative spatial correlations for the trends of CDD. All the HRPPs, especially ITPCAS, tend to overestimate the linear tendency of the CWD over the upper and middle reaches; therefore, the HRPPs strengthen the wetting tendency of the observations.

\section{Summary and concluding remarks}

In this study, six high-resolution precipitation products, TRMM 3B42, CMORPH-RAW, CMORPH-CRT, APHRO, CN05.1, and ITPCAS, are evaluated via a comparison with surface rain gauge observations recorded over the Heihe River basin at various temporal (daily, monthly, seasonal, annual) scales from 1998 to 2012. The accuracy of each HRPP is evaluated in terms of the mean climatology and extremes. The evaluation is based on two groups of rain gauge observations: one is the nonindependent meteorological stations, most of which have been assimilated into high-resolution products, and the other group is the hydrological stations, which have not been included in all HRPPs. To avoid the spatial coherence of nearby meteorological stations, only the hydrological stations that are far away from meteorological stations (a radius of $0.3^{\circ}$ and $0.5^{\circ}$ ) are used as independent ground truth. The validation of HRPPs is focused on the results at independent hydrological data, and all gauges regardless of station groups over each subregion are used for regional-scale assessment. It should be noted that great uncertainties are introduced by the scarcity of ground reference, especially over the downstream areas, where the comparison of HRPPs should be taken with caution.

All HRPPs are able to represent the overall spatial patterns of precipitation, although discrepancies between the HRPPs and observations are evident in winter. The HRPPs tend to overestimate the seasonal and annual precipitation amounts at most rain gauges, while underestimating the observed values at hydrological stations in winter and spring, especially for CMORPHCRT and APHRO. The different results of the two station groups may be attributed to the assimilation of meteorological records and complex topography over the HRB. The performance of the products varies significantly between the seasons and regions, although better precision is observed in summer and over the more humid upstream region. The satellite-based products (TRMM, CMORPH-RAW, and CMORPHCRT) cannot accurately reproduce the spatial distribution in winter with correlations below 0.2. The bias-correction procedures cannot bring significant improvement for CMORPH-CRT, which exhibits poor performance when compared with other HRPPs in all seasons except summer. The Taylor diagram based on independent data reveals that ITPCAS is the most consistent with observations, and it is followed by APHRO and CN05.1. 


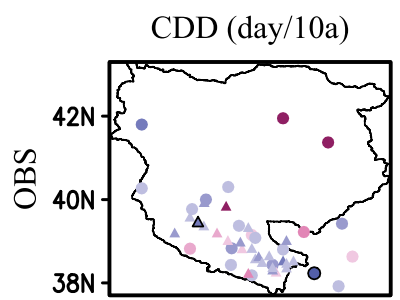

CWD (day/10a)
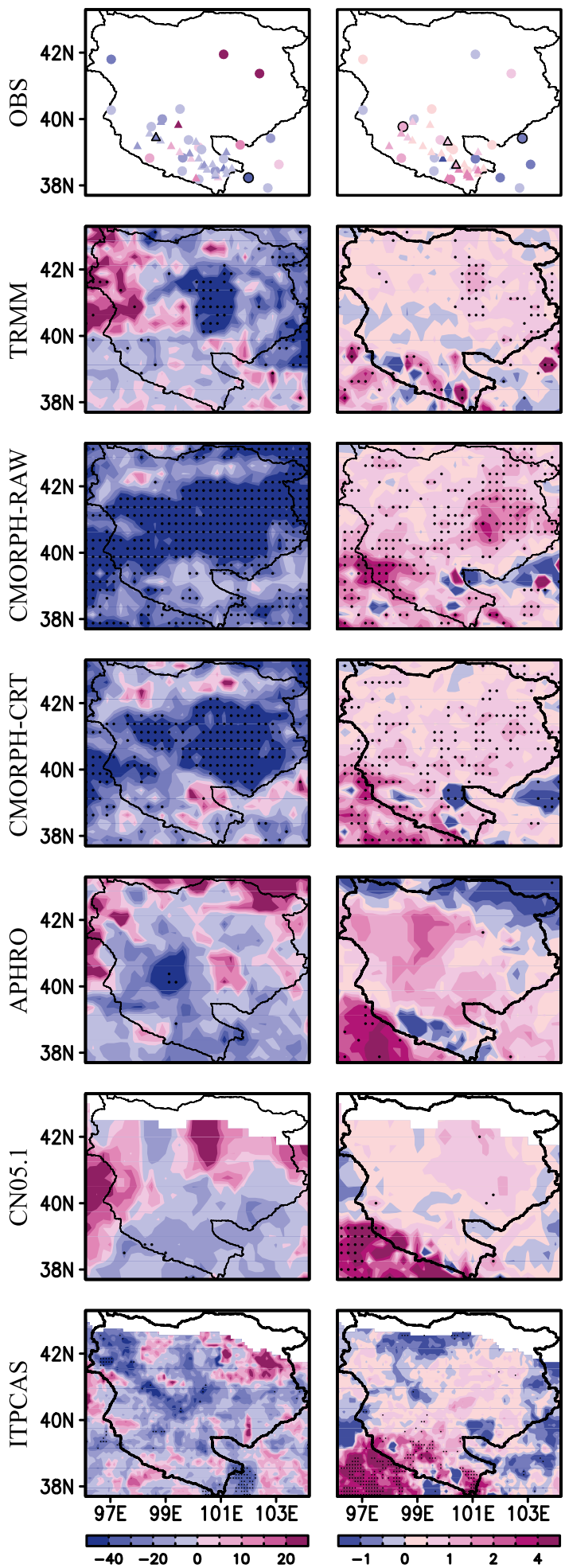

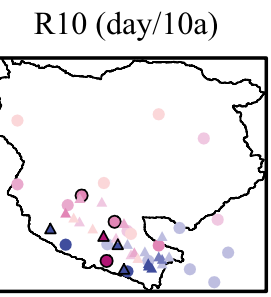

SDII (mm/day/10a)
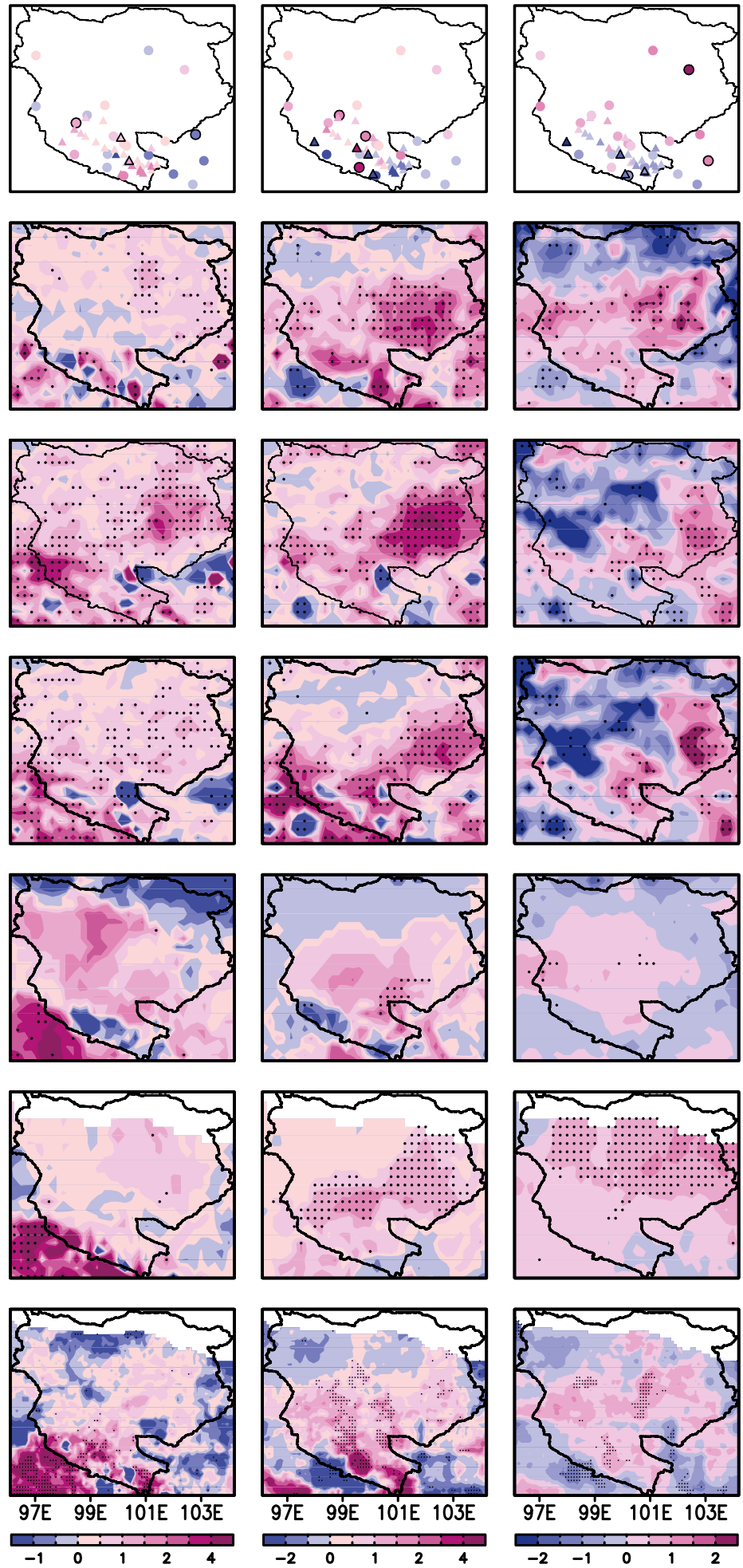

FIG. 11. Spatial patterns of the decadal trends for the extreme precipitation indices related to precipitation days [CDD, CWD, and R10; day $(10 \mathrm{a})^{-1}$ ] and intensity [SDII; mm day ${ }^{-1}(10 \mathrm{a})^{-1}$ ]. From top to bottom, the observations and results from TRMM, CMORPH-RAW, CMORPH-CRT, APHRO, CN05.1, and ITPCAS are illustrated. In addition to APHRO (1998-2007) and ITPCAS (1998-2010), the results of observations and other HRPPs are calculated for 1998-2012. Black edge for the observations and stippling for the HRPPs indicate trends that were significant at the $p=0.05$ level. 

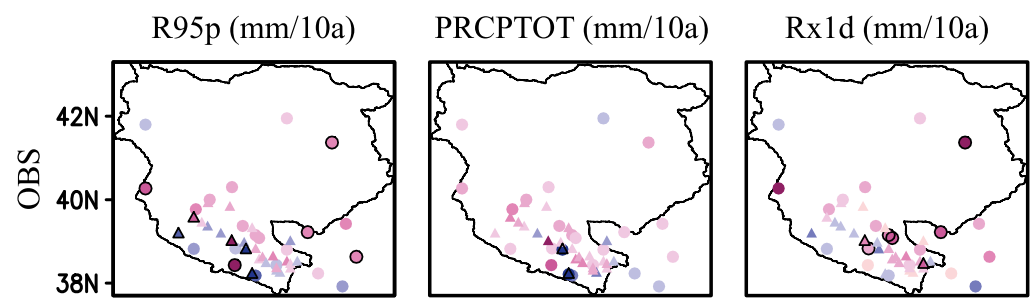

$\mathrm{Rx} 5 \mathrm{~d}(\mathrm{~mm} / 10 \mathrm{a})$
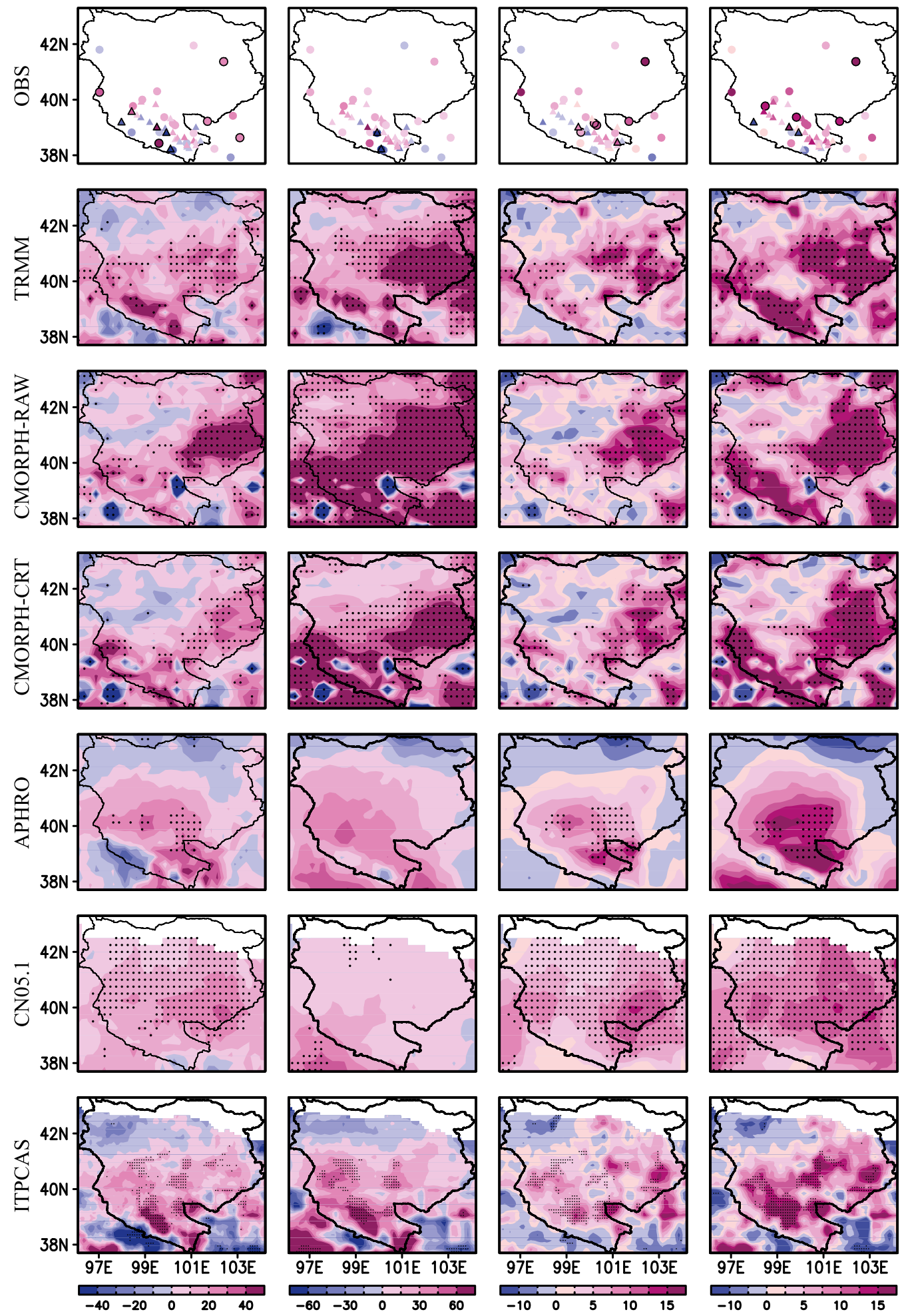

FIG. 12. As in Fig. 11, but for decadal trends of extreme indices related to precipitation amount [mm (10a) $\left.{ }^{-1}\right]$. 
The performance of TRMM is also favorable in autumn because it presents a relatively small bias and a large $r$ value compared to other products. CMORPH-CRT is comparable to TRMM in terms of $r$, RMSE, and the ability to detect precipitation events during summer, although it tends to generate more summer precipitation and less winter rainfall compared to independent observations.

Comparison between precipitation at independent hydrological stations and the nearest grid points show that the interannual rainfall variability is accurately reproduced by the gauge-based HRPPs, although the variability of winter precipitation is underestimated by all products. The TRMM outperforms two CMORPH products and presents better linear correlations with the gauge data, whereas the two CMORPH products generate opposite temporal patterns of observed precipitation in winter. The results of the annual cycle analysis show that all the HRPPs can reasonably estimate the observed precipitation and reproduce the peak that occurs in July at the hydrological stations. However, most products tend to overestimate the precipitation amounts during the warm season from June to September. The performance of HRPPs at different subregions is similar to that at independent gauges, the only exception being CMORPHRAW, which fails to reproduce the annual cycle with three peaks over the middle reaches, and the adjustment effect is clear for CMORPH-CRT. At the monthly time scale, TRMM shows a similar performance to that of gauge-based products in terms of temporal correlation and relative error, possibly because of the monthly biasadjustment algorithm based on GPCC data. However, the bias-correction procedure applied in CMORPH-CRT fails to reduce the RE and NRMSE of CMORPH-RAW, although it improves the temporal correlation compared to its satellite-only product at daily and monthly scales.

The estimated probability distribution of precipitation at independent hydrological stations and different subregions is consistent with the observations; however, outstanding discrepancies among the six products are detected in winter. All the HRPPs, especially gauge-based products, tend to overestimate the frequency of precipitation below $0.3 \mathrm{~mm} \mathrm{day}^{-1}$ and underestimate the occurrence of heavy rain in winter, whereas satellite-derived products present the adverse results in the downstream region. CMORPH-CRT increases the overdetection of precipitation intensity in the range of $0.1-0.3 \mathrm{~mm}$ day $^{-1}$ compared to the satellite-only CMORPH and is less consistent with observations than TRMM for light rain events at the hydrological stations. For the PDFs of summer precipitation, APHRO, CN05.1, and ITPCAS generate too few events of high intensity $\left(>12 \mathrm{~mm} \mathrm{day}^{-1}\right)$, and the satellite-based products, TRMM and CMORPH-CRT, demonstrate relatively closer PDFs with independent hydrological records in summer. The satisfactory performance of CMORPH-CRT with respect to good BS and $S_{\text {score }}$ statistics may be attributed to the PDFbased bias correction. However, more significant overestimation of light rain and worse PDF-based scores are detected by CMORPH-CRT after gauge adjustment in winter, possibly due to the poor detection skill of the two CMORPH products during cold season.

Analysis at the daily time scale indicates that the ability of HRPPs in detecting precipitation occurrence presents strong seasonal variations with better performance during summer. The satellite-based HRPPs suffer from missed detections and false alarms (low POD and high FAR) especially in winter, with the two CMORPH products being more and TRMM being less significant. That is to say, the CMORPH products tend to detect less and fail more during the cold season, and the bias-correction technique fails to improve the skill of detecting precipitation, although it can slightly improve the temporal correlation. A possible reason for the deteriorated performance of satellite-derived products in winter is the limited detection capability of the PMW sensor for cold season precipitation. The comparison with independent data indicates that gauge-based HRPPs, especially APHRO, demonstrate a superior detection capability with relatively high POD and CSI, although ITPCAS and CN05.1 tend to falsely detect precipitation events with FAR around 0.7 in summer. The high FAR values of all products may be related to the spatial representativeness issue of gridded rainfall estimates and point-scale observations. These indices should be taken with caution, and more studies including denser rain gauge networks are needed to evaluate the ability of HRPPs at daily time scales.

The HRPPs can reasonably reproduce the spatial distributions of extreme precipitation indices. Although the satellite-based products tend to overestimate the observed R95p, PRCPTOT, and CWD and underestimate the CDD and SDII compared with the observations, TRMM produces more accurate descriptions of the phases of R10, SDII, and Rx1d. All products can basically estimate the wetting tendency over the entire basin with decreasing trends in the CDD and opposite trends for other extreme wet indices, although the magnitude of the trends present differences from the observations. Most results with statistically significant trends in HRPPs are captured over the areas where no gauge references are available and there are not robust trends in the rain gauge data, which implies that the coarse density of the reference gauges limits the validation of HRPPs in terms of the change trends of the extreme indices, and the HRPPs should be considered 
with caution when analyzing the long-term trend of precipitation extremes over the HRB.

In summary, high-resolution gridded data can be a good alternative resource for precipitation information over the HRB. Among all the gauge-based products evaluated, APHRO provides best estimates with respect to climatology, temporal variation, precipitation detection skill, PDFs, and extreme events, and the results of CN05.1 and ITPCAS are consistent with the observations as well. However, the satellite-derived products generally present poor accuracy with relatively low correlations and high systematic biases, especially in winter. The less-than-desirable performance of the PMW sensors in detecting precipitation, especially in winter, is the major challenge for satellitebased products, especially for the two CMORPH products over the arid and semiarid HRB. It is noteworthy that the accuracy of TRMM is favorable for autumn precipitation and for the spatial patterns of extreme indices, which may be related to the combination of IR data and the monthly bias-correction procedure. The accuracy of the satellite-only CMORPH could be improved through the gauge-adjusted algorithms. However, relatively larger biases are detected for CMORPH-CRT than for other products, and the adjustment fails to improve the rainfall detection capability of the product. Overall, the HRPPs have application potential for areas with sparse rain gauges and complex terrain because of their wide coverage and high resolution. These datasets can facilitate the study of large areas and long-term spatiotemporal features of precipitation, and they can improve the reliability of climate change research as well. However, caution is needed while analyzing the long-term trends of extreme events.

Acknowledgments. The research is supported by the National Natural Science Foundation of China (91425304, 91525101 and 41375075) and the Jiangsu Collaborative Innovation Center for Climate Change. Thanks to the China Meteorological Administration (CMA) for providing the observational data $\left(\mathrm{SURF}_{-}\right.$ CLI_CHN_MUL_DAY, V3.0) and CN05.1, and other data providers such as the National Natural Science Foundation of China (NSFC) for the provision of hydrological records, the NASA Goddard Space Flight Center Distributed Active Archive Center for provision of the TRMM dataset, the NOAA/Climate Prediction Center (CPC) for providing the CMORPH data, and the APHRODITE project (http://www. chikyu.ac.jp/precip/). Thanks also are given to the Third Pole Environment Database for providing the ITPCAS data and the Cold and Arid Regions Sciences Data Center at Lanzhou (http://westdc.westgis.ac.cn) for the provision of boundary data. Constructive comments and suggestions from the editor and anonymous reviewers are acknowledged.

\section{APPENDIX}

\section{List of Acronyms}

\begin{tabular}{ll} 
APHRODITE & $\begin{array}{c}\text { Asian Precipitation-Highly Resolved } \\
\text { Observational Data Integration } \\
\text { Toward Evaluation of Water } \\
\text { Resources }\end{array}$ \\
BS & $\begin{array}{l}\text { Brier score } \\
\text { CDD }\end{array}$ \\
CMORPH & $\begin{array}{l}\text { Consecutive dry days } \\
\text { Climate Prediction Center morphing } \\
\text { technique }\end{array}$ \\
CMORPH-CRT & The gauge-corrected version of \\
& CMORPH \\
CMORPH- & The satellite-only version of \\
RAW & CMORPH \\
CNO5.1 & National Climate Center of China \\
\multicolumn{2}{c}{ Meteorological Administration } \\
CSI & Critical success index \\
FAR & False alarm ratio \\
HRB & Heihe River basin \\
HRPPs & High-resolution precipitation products \\
ITPCAS & Institute of Tibetan Plateau Research, \\
\multicolumn{2}{c}{ Chinese Academy of Sciences } \\
MRE & Mean relative error \\
NRMSE & Normalized root-mean-square error \\
PDF & Probability density function \\
PMW & Passive microwave \\
POD & Probability of detection \\
RE & Relative error \\
RMSE & Root-mean-square error \\
$S_{\text {score }}$ & Significance score \\
TRMM & Tropical Rainfall Measuring Mission \\
&
\end{tabular}

\section{REFERENCES}

Accadia, C., S. Mariani, M. Casaioli, A. Lavagnini, and A. Speranza, 2003: Sensitivity of precipitation forecast skill scores to bilinear interpolation and a simple nearest-neighbor average method on high-resolution verification grids. Wea. Forecasting, 18, 918-932, doi:10.1175/1520-0434(2003)018<0918: SOPFSS $>2.0 . \mathrm{CO} ; 2$.

Andermann, C., S. Bonnet, and R. Gloaguen, 2011: Evaluation of precipitation data sets along the Himalayan front. Geochem. Geophys. Geosyst., 12, Q07023, doi:10.1029/2011GC003513.

Cao, L., and Y. X. Dou, 2005: The spatial and temporal characteristics and forecasting method of precipitation in Heihe Field (in Chinese). J. Arid Meteor., 23, 35-38

Cavazos, T., 2000: Using self-organizing maps to investigate extreme climate events: An application to wintertime 
precipitation in the Balkans. J. Climate, 13, 1718-1732, doi:10.1175/1520-0442(2000)013<1718:USOMTI>2.0.CO;2.

Cheng, A., Q. Feng, G. Fu, J. Zhang, Z. Li, M. Hu, and G. Wang, 2015: Recent changes in precipitation extremes in the Heihe River Basin, northwest China. Adv. Atmos. Sci., 32, 13911406, doi:10.1007/s00376-015-4199-3.

Cheng, G. D., 2002: Study on the sustainable development in Heihe River watershed from the view of ecological economics (in Chinese). J. Glaciol. Geocryol., 24, 335-343.

- X. Li, W. Z. Zhao, Z. M. Xu, Q. Feng, S. C. Xiao, and H. L. Xiao, 2014: Integrated study of the water-ecosystem-economy in the Heihe River Basin. Natl. Sci. Rev., 1, 413-428, doi:10.1093/nsr/nwu017.

Ding, R., F. C. Wang, J. Wang, and J. N. Liang, 2009: Analysis on spatial-temporal characteristics of precipitation in Heihe River Basin and forecast evaluation in recent 47 years (in Chinese). J. Desert Res., 29, 335-341.

Ding, Y. J., B. S. Ye, and W. J. Zhou, 1999: Temporal and spatial precipitation distribution in the Heihe catchment, northwest China, during the past 40 a (in Chinese). J. Glaciol. Geocryol., 21, 42-48.

Donat, M. G., L. V. Alexander, H. Yang, I. Durre, R. Vose, and J. Caesar, 2013: Global land-based datasets for monitoring climatic extremes. Bull. Amer. Meteor. Soc., 94, 997-1006, doi:10.1175/BAMS-D-12-00109.1.

Ebert, E. E., J. E. Janowiak, and C. Kidd, 2007: Comparison of near-real-time precipitation estimates from satellite observations and numerical models. Bull. Amer. Meteor. Soc., 88, 47-64, doi:10.1175/BAMS-88-1-47.

Ghajarnia, N., A. Liaghat, and P. D. Arasteh, 2015: Comparison and evaluation of high resolution precipitation estimation products in Urmia Basin-Iran. Atmos. Res., 158-159, 50-65, doi:10.1016/j.atmosres.2015.02.010.

Guo, H., S. Chen, A. Bao, J. Hu, A. S. Gebregiorgis, X. Xue, and X. Zhang, 2015: Inter-comparison of high-resolution satellite precipitation products over central Asia. Remote Sens., 7, 7181-7211, doi:10.3390/rs70607181.

Guo, X., L. Wang, and L. Tian, 2016: Spatio-temporal variability of vertical gradients of major meteorological observations around the Tibetan Plateau. Int. J. Climatol., 36, 1901-1916, doi:10.1002/joc.4468.

Habib, E., A. Henschke, and R. F. Adler, 2009: Evaluation of TMPA satellite-based research and real-time rainfall estimates during six tropical-related heavy rainfall events over Louisiana, USA. Atmos. Res., 94, 373-388, doi:10.1016/j.atmosres.2009.06.015.

Han, Z. Y., and T. J. Zhou, 2012: Assessing the quality of APHRODITE high-resolution daily precipitation dataset over contiguous China (in Chinese). Chin. J. Atmos. Sci., 36, 361-373, doi:10.3878/j.issn.1006-9895.2011.11043

He, J., 2010: Development of a surface meteorological dataset of China with high temporal and spatial resolution (in Chinese). M. S. dissertation, Institute of Tibetan Plateau Research, Chinese Academy of Science, $96 \mathrm{pp}$.

He, S. W., Z. T. Nan, and Y. T. Hou, 2015: Accuracy evaluation of two precipitation datasets over upper reach of Heihe River Basin, northwestern China. Sci. Cold Arid Reg., 7, 157-169, http://www. scar.ac.cn/hhkxen/ch/reader/view_abstract.aspx?file_no $=20150206$.

Huffman, G. J., and D. T. Bolvin, 2013: TRMM and other data precipitation data set documentation. NASA Tech Rep. TRMM 3B42_3B43, 44 pp., https://pmm.nasa.gov/sites/ default/files/document_files/3B42_3B43_doc_V7.pdf.

Hussain, Y., F. Satgé, M. B. Hussain, H. Martinez-Carvajal, M. P. Bonnet, M. Cárdenas-Soto, H. L. Roig, and G. Akhter, 2017:
Performance of CMORPH, TMPA, and PERSIANN rainfall datasets over plain, mountainous, and glacial regions of Pakistan. Theor. Appl. Climatol, doi:10.1007/ s00704-016-2027-z, in press.

Jiang, S., L. Ren, B. Yong, Y. Hong, X. Yang, and F. Yuan, 2016: Evaluation of latest TMPA and CMORPH precipitation products with independent rain gauge observation networks over high-latitude and low-latitude basins in China. Chin Geogr. Sci., 26, 439-455, doi:10.1007/s11769-016-0818-x.

Joyce, R. J., J. E. Janowiak, P. A. Arkin, and P. Xie, 2004: CMORPH: A method that produces global precipitation estimates from passive microwave and infrared data at high spatial and temporal resolution. J. Hydrometeor., 5, 487-503, doi:10.1175/1525-7541(2004)005<0487:CAMTPG >2.0.CO;2.

Kidd, C., P. Bauer, J. Turk, G. J. Huffman, R. Joyce, K. L. Hsu, and D. Braithwaite, 2012: Intercomparison of high-resolution precipitation products over northwest Europe. J. Hydrometeor., 13, 67-83, doi:10.1175/JHM-D-11-042.1.

Li, X., and Coauthors, 2013: Heihe Watershed Allied Telemetry Experimental Research (HiWATER): Scientific objectives and experimental design. Bull. Amer. Meteor. Soc., 94, 1145-1160, doi:10.1175/BAMS-D-12-00154.1.

Liu, J. F., R. S. Chen, C. T. Han, and C. P. Tan, 2010: Evaluating TRMM multi-satellite precipitation analysis using gauge precipitation and MODIS snow-cover products (in Chinese). Adv. Water Sci., 21, 343-348.

Liu, Y., J. Y. Sun, H. M. Song, Q. F. Cai, G. Bao, and X. X. Li, 2010: Tree-ring hydrologic reconstructions for the Heihe River watershed, western China since AD 1430. Water Res., 44, 2781-2792, doi:10.1016/j.watres.2010.02.013.

Ma, W., Y. Ma, Z. Hu, Z. Su, J. Wang, and H. Ishikawa, 2011: Estimating surface fluxes over middle and upper streams of the Heihe River Basin with ASTER imagery. Hydrol. Earth Syst. Sci., 15, 1403-1413, doi:10.5194/hess-15-1403-2011.

Maggioni, V., P. C. Meyers, and M. D. Robinson, 2016: A review of merged high-resolution satellite precipitation product accuracy during the Tropical Rainfall Measuring Mission (TRMM) era. J. Hydrometeor., 17, 1101-1117, doi:10.1175/JHM-D-15-0190.1.

McEvoy, D. J., J. F. Mejia, and J. L. Huntington, 2014: Use of an observation network in the Great Basin to evaluate gridded climate data. J. Hydrometeor., 15, 1913-1931, doi:10.1175/JHM-D-14-0015.1.

New, M., M. Todd, M. Hulme, and P. Jones, 2001: Precipitation measurements and trends in the twentieth century. Int. J. Climatol., 21, 1889-1922, doi:10.1002/joc.680.

Pan, X., X. Li, K. Yang, J. He, Y. Zhang, and X. Han, 2014: Comparison of downscaled precipitation data over a mountainous watershed: A case study in the Heihe River Basin. J. Hydrometeor., 15, 1560-1574, doi:10.1175/JHM-D-13-0202.1.

Peng, B., J. C. Shi, W. Ni-Meister, T. J. Zhao, and D. B. Ji, 2014: Evaluation of TRMM Multisatellite Precipitation Analysis (TMPA) products and their potential hydrological application at an arid and semiarid basin in China. IEEE J. Sel. Top. Appl. Earth Obs. Remote Sens., 7, 3915-3930, doi:10.1109/JSTARS.2014.2320756.

Perkins, S. E., A. J. Pitman, N. J. Holbrook, and J. McAneney, 2007: Evaluation of the AR4 climate models' simulated daily maximum temperature, minimum temperature, and precipitation over Australia using probability density functions. J. Climate, 20, 4356-4376, doi:10.1175/JCLI4253.1.

Peterson, T. C., and M. J. Manton, 2008: Monitoring changes in climate extremes: A tale of international collaboration. Bull. Amer. Meteor. Soc., 89, 1266-1271, doi:10.1175/2008BAMS2501.1.

Prakash, S., A. K. Mitra, I. M. Momin, D. S. Pai, E. N. Rajagopal, and S. Basu, 2015: Comparison of TMPA-3B42 versions 6 and 
7 precipitation products with gauge-based data over India for the southwest monsoon period. J. Hydrometeor., 16, 346-362, doi:10.1175/JHM-D-14-0024.1.

Salio, P., M. P. Hobouchian, Y. G. Skabar, and D. Vila, 2015: Evaluation of high-resolution satellite precipitation estimates over southern South America using a dense rain gauge network. Atmos. Res., 163, 146-161, doi:10.1016/j.atmosres.2014.11.017.

Sang, Y. F., Z. Wang, C. Liu, and T. Gong, 2013: Temporal-spatial climate variability in the headwater drainage basins of the Yangtze River and Yellow River, China. J. Climate, 26, 50615071, doi:10.1175/JCLI-D-12-00523.1.

Satgé, F., M. P. Bonnet, M. Gosset, J. Molina, W. H. Y. Lima, R. P. Zolá, F. Timouk, and J. Garnier, 2016: Assessment of satellite rainfall products over the Andean plateau. Atmos. Res., 167, 1-14, doi:10.1016/j.atmosres.2015.07.012.

Schaefer, J. T., 1990: The critical success index as an indicator of warning skill. Wea. Forecasting, 5, 570-575, doi:10.1175/ 1520-0434(1990)005<0570:TCSIAA $>2.0$. CO;2.

Schneider, U., A. Becker, P. Finger, A. Meyer-Christoffer, M. Ziese, and B. Rudolf, 2014: GPCC's new land surface precipitation climatology based on quality-controlled in situ data and its role in quantifying the global water cycle. Theor. Appl. Climatol., 115, 15-40, doi:10.1007/s00704-013-0860-x.

Shen, Y., and Y. Chen, 2010: Global perspective on hydrology, water balance, and water resources management in arid basins. Hydrol. Processes, 24, 129-135, doi:10.1002/hyp.7428.

_ - A. Xiong, Y. Wang, and P. Xie, 2010: Performance of highresolution satellite precipitation products over China J. Geophys. Res., 115, D02114, doi:10.1029/2009JD012097.

Sillmann, J., V. V. Kharin, X. Zhang, F. W. Zwiers, and D. Bronaugh, 2013a: Climate extremes indices in the CMIP5 multimodel ensemble: Part 1. Model evaluation in the present climate. J. Geophys. Res. Atmos., 118, 1716-1733, doi:10.1002/ jgrd.50203.

- - , F. W. Zwiers, X. Zhang, and D. Bronaugh, 2013b: Climate extremes indices in the CMIP5 multimodel ensemble: Part 2. Future climate projections. J. Geophys. Res. Atmos., 118, 2473-2493, doi:10.1002/jgrd.50188.

Silva, V. B., V. E. Kousky, W. Shi, and R. W. Higgins, 2007: An improved gridded historical daily precipitation analysis for Brazil. J. Hydrometeor., 8, 847-861, doi:10.1175/JHM598.1.

Sun, Y., S. Solomon, A. Dai, and R. W. Portmann, 2006: How often does it rain? J. Climate, 19, 916-934, doi:10.1175/JCLI3672.1.

Tan, M. L., A. L. Ibrahim, Z. Duan, A. P. Cracknell, and V. Chaplot, 2015: Evaluation of six high-resolution satellite and ground-based precipitation products over Malaysia. Remote Sens., 7, 1504-1528, doi:10.3390/rs70201504.

Taylor, K. E., 2001: Summarizing multiple aspects of model performance in a single diagram. J. Geophys. Res., 106, 71837192, doi:10.1029/2000JD900719.

Thiemig, V., R. Rojas, M. Zambrano-Bigiarini, V. Levizzani, and A. D. Roo, 2012: Validation of satellite-based precipitation products over sparsely gauged African river basins. J. Hydrometeor., 13, 1760-1783, doi:10.1175/JHM-D-12-032.1.

Tian, Y., C. D. Peters-Lidard, R. F. Adler, T. Kubota, and T. Ushio, 2010: Evaluation of GSMaP precipitation estimates over the contiguous United States. J. Hydrometeor., 11, 566-574, doi:10.1175/2009JHM1190.1.

Turk, F. J., P. Arkin, E. E. Ebert, and M. R. Sapiano, 2008: Evaluating high-resolution precipitation products. Bull. Amer. Meteor. Soc., 89, 1911-1916, doi:10.1175/2008BAMS2652.1.
Villarini, G., P. V. Mandapaka, W. F. Krajewski, and R. J. Moore, 2008: Rainfall and sampling uncertainties: A rain gauge perspective. J. Geophys. Res., 113, D11102, doi:10.1029/ 2007JD009214.

Wilks, D. S., 2011: Statistical Methods in the Atmospheric Sciences. 2nd ed. Academic Press, 627 pp.

Wu, J., and X. J. Gao, 2013: A gridded daily observation dataset over China region and comparison with the other datasets (in Chinese). Chin. J. Geophys., 56, 1102-1111, doi:10.6038/cjg20130406.

Wu, X. J., M. X. Yang, H. B. Wu, Y. W. Wu, and X. J. Wang, 2013: Verifying and applying the TRMM TMPA in Heihe River Basin (in Chinese). J. Glaciol. Geocryol., 35, 310-319, doi:10.7522/j.issn.1000-0240.2013.0037.

Xie, P., and P. A. Arkin, 1995: An intercomparison of gauge observations and satellite estimates of monthly precipitation. J. Appl. Meteor., 34, 1143-1160, doi:10.1175/ 1520-0450(1995)034<1143:AIOGOA > 2.0.CO;2.

—, M. Chen, S. Yang, A. Yatagai, T. Hayasaka, Y. Fukushima, and C. Liu, 2007: A gauge-based analysis of daily precipitation over East Asia. J. Hydrometeor., 8, 607-626, doi:10.1175/JHM583.1.

, S.-H. Yoo, R. Joyce, and Y. Yarosh, 2011: Bias-corrected CMORPH: A 13-year analysis of high-resolution global precipitation. Geophysical Research Abstracts, Vol. 13, Abstract EGU2011-1809, http://meetingorganizer.copernicus.org/ EGU2011/EGU2011-1809.pdf.

—, R. Joyce, S. Wu, S. H. Yoo, Y. Yarosh, F. Sun, and R. Lin, 2017: Reprocessed, bias-corrected CMORPH global high-resolution precipitation estimates from 1998. J. Hydrometeor., 18, 1617-1641, doi:10.1175/JHM-D-16-0168.1.

Xiong, Z., and X. D. Yan, 2013: Building a high-resolution regional climate model for the Heihe River Basin and simulating precipitation over this region. Chin. Sci. Bull., 58, 4670-4678, doi:10.1007/s11434-013-5971-3.

Yang, Q., and Z. G. Ma, 2014: Comparison of different precipitation observations in Xinjiang and its possible cause analysis (in Chinese). Climatic Environ. Res., 19, 452-462.

Yang, Y., and Y. Luo, 2014: Evaluating the performance of remote sensing precipitation products CMORPH, PERSIANN, and TMPA, in the arid region of northwest China. Theor. Appl. Climatol., 118, 429-445, doi:10.1007/s00704-013-1072-0.

Yatagai, A., O. Arakawa, K. Kamiguchi, H. Kawamoto, M. I. Nodzu, and A. Hamada, 2009: A 44-year daily gridded precipitation dataset for Asia based on a dense network of rain gauges. Sci. Online Lett. Atmos., 5, 137-140, doi:10.2151/sola.2009-035.

, K. Kamiguchi, O. Arakawa, A. Hamada, N. Yasutomi, and A. Kitoh, 2012: APHRODITE: Constructing a long-term daily gridded precipitation dataset for Asia based on a dense network of rain gauges. Bull. Amer. Meteor. Soc., 93, 1401-1415, doi:10.1175/BAMS-D-11-00122.1.

You, Q., and Coauthors, 2011: Changes in daily climate extremes in China and their connection to the large scale atmospheric circulation during 1961-2003. Climate Dyn., 36, 2399-2417, doi:10.1007/s00382-009-0735-0.

Zeng, Q., and B. Yang, 2016: Comparing meteorological records between mountainous and valley bottom sites in the upper reaches of the Heihe River, northwestern China: Implications for dendroclimatology. Theor. Appl. Climatol., 128, 407-419, doi:10.1007/s00704-015-1717-2.

Zhou, T., R. Yu, H. Chen, A. Dai, and Y. Pan, 2008: Summer precipitation frequency, intensity, and diurnal cycle over China: A comparison of satellite data with rain gauge observations. J. Climate, 21, 3997-4010, doi:10.1175/2008JCLI2028.1. 